\title{
Smart Buildings: Business Case and Action Plan
}

\author{
Paul Ehrlich ${ }^{1}$ and Rick Diamond ${ }^{2}$
}

${ }^{1}$ Building I ntelligence Group

St. Paul, MN

\author{
${ }^{2}$ Environmental Energy Technologies Division \\ Indoor Environment Department \\ Lawrence Berkeley National Laboratory \\ Berkeley, CA 94720
}

April 2009-05-28

The work described in this report was funded by the U.S. General Services Administration and the Federal Energy Management Program of the U.S. Department of Energy under Contract No. DE-AC02-05CH11231. 


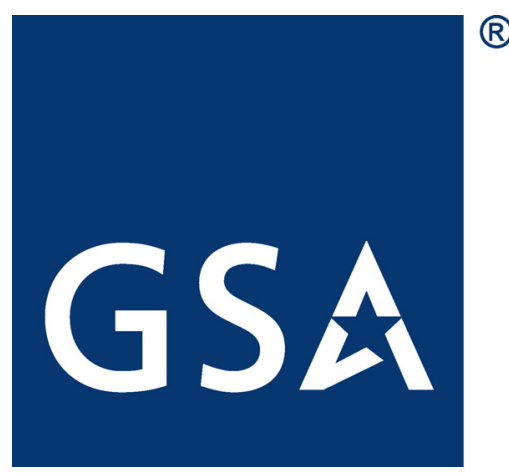

\title{
Smart Buildings: Business Case and Action Plan
}

\author{
Prepared for \\ General Services Administration \\ By
}

Paul Ehrlich, Building Intelligence Group, and

Rick Diamond, LBNL

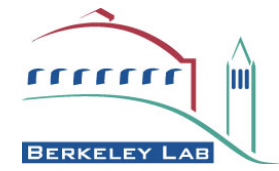

(651) 204-0105

info@buildingintelligencegroup.com

www.buildingintelligencegroup.com 


\section{Disclaimer}

This document was prepared as an account of work sponsored by the United States Government. While this document is believed to contain correct information, neither the United States Government nor any agency thereof, nor The Regents of the University of California, nor any of their employees, makes any warranty, express or implied, or assumes any legal responsibility for the accuracy, completeness, or usefulness of any information, apparatus, product, or process disclosed, or represents that its use would not infringe privately owned rights. Reference herein to any specific commercial product, process, or service by its trade name, trademark, manufacturer, or otherwise, does not necessarily constitute or imply its endorsement, recommendation, or favoring by the United States Government or any agency thereof, or The Regents of the University of California. The views and opinions of authors expressed herein do not necessarily state or reflect those of the United States Government or any agency thereof, or The Regents of the University of California.

Ernest Orlando Lawrence Berkeley National Laboratory is an equal opportunity employer.

The work described in this report was funded by the U.S. General Services Administration and the Federal Energy Management Program of the U.S. Department of Energy under Contract No. DE-AC02-05CH11231. 


\title{
Acknowledgements
}

This project has relied on input from a large group of individuals within GSA. This would not have been possible without the focused effort of GSA's core project team and our project consultants Lawrence Berkeley National Laboratory, Building Intelligence Group and Noblis. This core group includes:

\author{
General Services Administration \\ Anthony Costa \\ Benjamin Kochanski \\ Arun Majumdar \\ Cynthia C. Frias \\ Chuck Ehrlich \\ David S. Marciniak \\ Jeff Seewald \\ Debra J. Bicker \\ Paul Ehrlich \\ Denise M. Cheslack \\ Rick Diamond \\ Diane L. Herdt \\ Riva Kupritz \\ Douglas L. York \\ Karl O. Krumbholz \\ Steve Selkowitz \\ Kevin Kampschroer \\ Noblis \\ Kevin M. Powell \\ Ed Bowen \\ Lenora A. Bisacquino \\ Gerry Brosnan \\ Mark V. Ewing \\ Martin J. Weiland \\ Matt Brown \\ Patrick Fee \\ Patricia Cheng \\ Peggy $\mathrm{H}$. Ho \\ Reggie Gavett \\ Rita J. Williams \\ Robert D. Harding \\ Robert D. Shaw \\ Scott M. Glaser \\ Tamela L. Riggs
}

LBNL/Building Intelligence Group 


\section{Smart Buildings: Business Case and Action Plan}

\section{Contents}

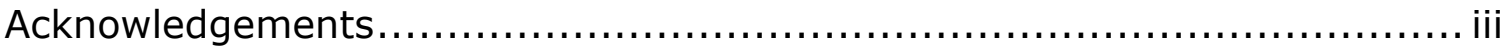

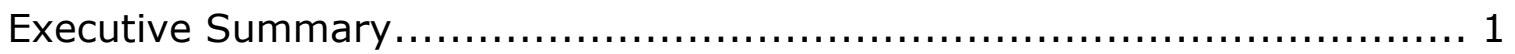

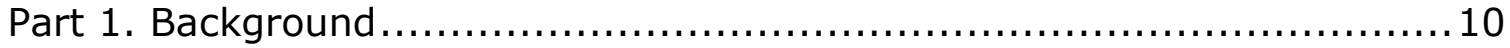

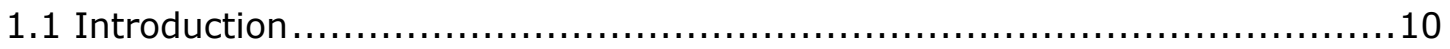

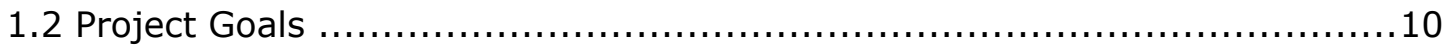

1.3 What is a Smart Building? ......................................................... 10

1.4 What has been GSA's involvement in Smart Buildings? ..........................13

1.5 How will Smart Buildings compliment efforts funded by the Recovery Act? .. 14

1.6 Why would GSA pursue Smart Buildings? ......................................... 15

1.7 What are the Smart Building challenges? ........................................ 17

1.8 What are the GSA specific challenges? ............................................. 18

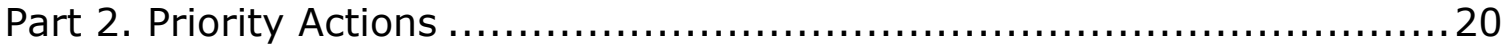

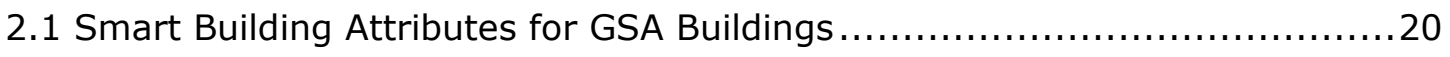

2.2 Smart Building Design and Operation Recommendations .......................22

Part 3. Costs, Investment, and Savings ....................................... 25

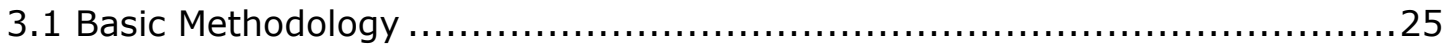

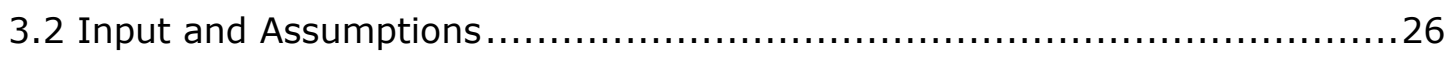

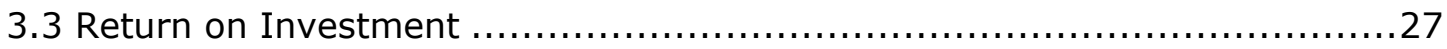

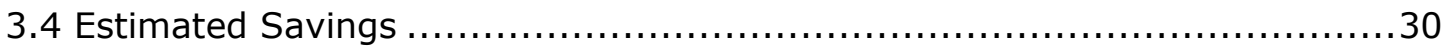

3.5 Estimated Costs and Investment...................................................

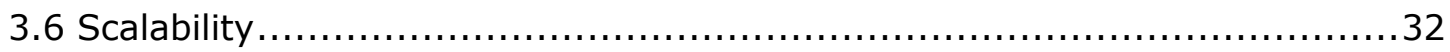

Part 4. Recommended Action Plan ............................................. 33

Revision History of the Report ................................................ 38

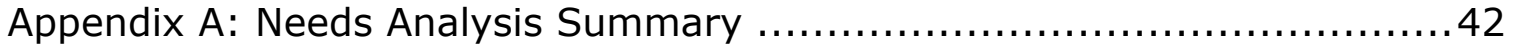

Appendix B: Technical Strategies for Smart Buildings ......................... 46

Appendix C: Financial Analysis Assumptions...................................56

Appendix D: Detailed Financial Analysis Summary and Pro-forma.............61 61

Appendix E: Action Plan Scenarios ............................................. 64

Appendix F: Network Infrastructure Options $\ldots \ldots \ldots \ldots \ldots \ldots \ldots \ldots \ldots \ldots \ldots \ldots \ldots 71$ 


\section{Executive Summary}

\section{What is new in this version?}

Changes from the January 2009 draft include:

\section{Part 1. Background}

- Introduced the opportunities for integrating Smart Building strategies with public building renewal under the Recovery Act.

- Included training and certification program considerations under Smart Building challenges regarding contractors, integrators, and operators.

Part 2. Priority Actions

- Under Recommendation \#1, addressed the potential impact of the High Performance Building Core inclusion in public building renewal under ARRA.

- Under Recomendation\#2, added demand response.

\section{Part 3. Costs, Investment and Savings}

- Updated financial analysis for all tables.

- Added section 3.2 Input and Assumptions to show sources of operating cost and scope assumptions.

- Updated section 3.3 Investment and Return.

- Reduced energy benefits and savings associated with the High Performance Building Core based on energy savings from efforts funded by the Recovery Act.

- Reduced the cost of the High Performance Building Core to reflect the cost of the network infrastructure element only, per the assumption that the other elements will be funded by the Recovery Act and implemented as part of public building renewal.

- Removed productivity benefits from the financial analysis.

- Changed the analysis to depict energy and operations benefits independently, and energy and operations benefits combined.

- Added scalability analysis to show impact of building area impacted on payback period.

\section{Part 4. Recommended Action Plan}

- Updated the action plan to be consistent with efforts under the Recovery Act.

- Added Scenario Analysis for evaluating pilot and deployment alternatives.

Table 4-2 and Table 4-3 in the main report provide the detailed changes and the impacts of these changes. 


\section{Part 1: Background}

A "Smart Building" integrates major building systems on a common network and shares information and functionality between systems to improve energy efficiency, operational effectiveness, and occupant satisfaction.

What is a Smart Building? Figure ES-1 shows three levels of Smart Building integration starting with a base of optimized building systems, which supports a middle tier of converged networks and systems integration within each building, which enables a top level of enterprise integration and management across multiple buildings.

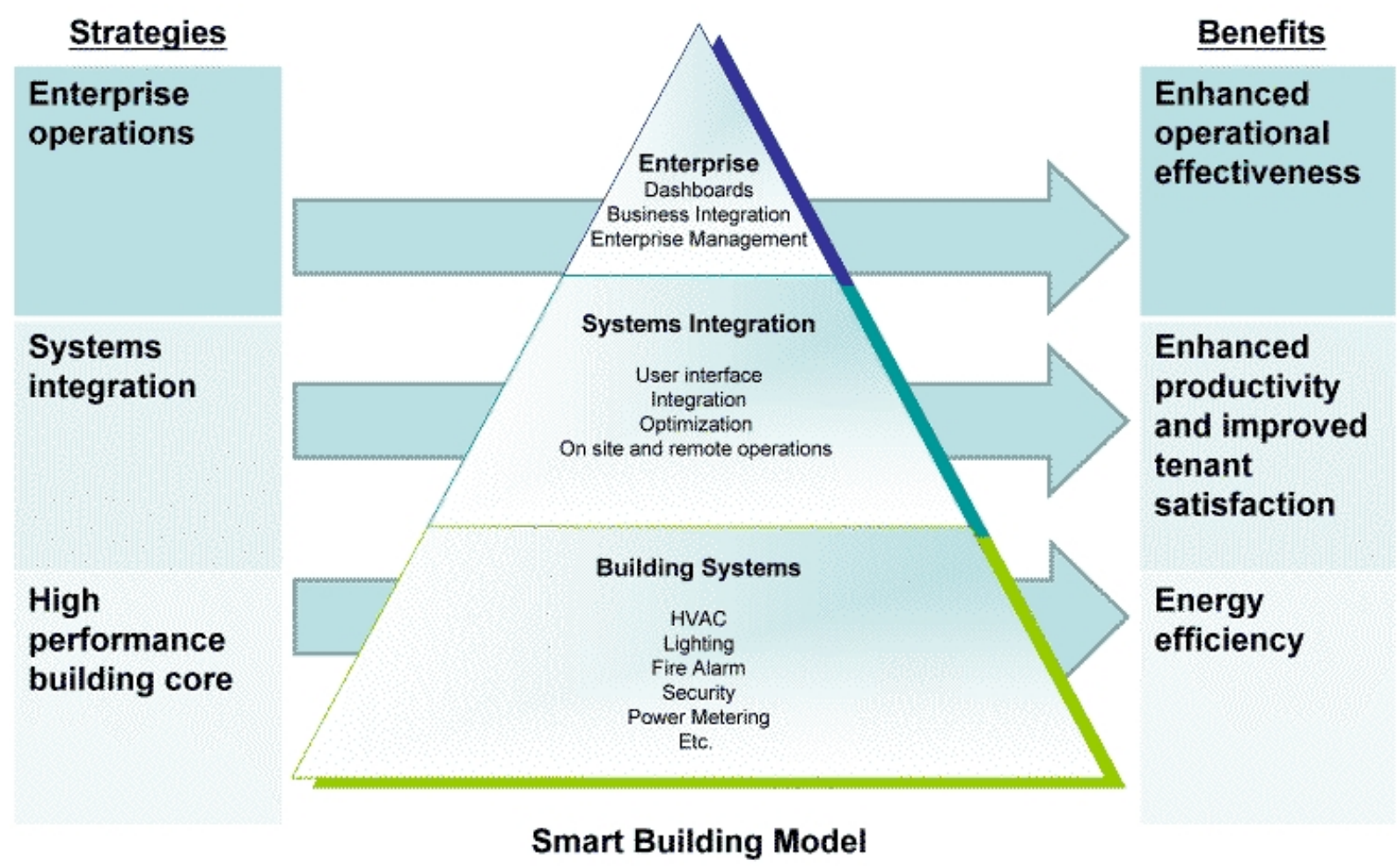

Figure ES-1: Model of the Hierarchy of Smart Building Strategies

The major Smart Buildings benefits fall into three categories:

- Improved energy efficiency

- Enhanced operational effectiveness

- Increased tenant satisfaction 
There are major challenges specific to GSA in pursuing a Smart Buildings strategy:

- Smart Building complexity may overwhelm current operations and maintenance resources

- Current P-100 standards do not allow cross-system control or optimization

- Existing GSA buildings may need extensive and comprehensive upgrades

- Existing challenges with operations contractors' performance and turnover may impact the ability to maintain Smart Building performance

- GSA will need a national standard for Computerized Maintenance Management Systems (CMMS)

\section{What is the relationship between Smart Buildings and public building renewal under the Recovery Act?}

For GSA buildings addressed by efforts in accordance with the American Recovery and Reinvestment Act, it is assumed that the first level of the Smart Building model, the High Performance Building Control Core, is put in place as part of public building renewal, and that an additional investment is required to add network infrastructure for building systems, systems integration, and enterprise management.

The total scope of Smart Buildings is approximately the same as the scope of efforts in accordance with the Recovery Act: nominally 300 buildings comprising 150 million square feet of gross floor space.

\section{Part 2: Priority Actions}

This report identifies five recommendations for achieving smart buildings:

Recommendation \# 1: Develop a High Performance Building Control Core

Recommendation \#2: Integrate the Relevant Building Systems

Recommendation \#3: Develop an Enterprise Management Strategy based on Building Operations Centers

Recommendation \#4: Use Integrated Design for All New Buildings

Recommendation \#5: Upgrade Existing Buildings Comprehensively 


\section{GSA}

\section{Part 3. Costs, Investment, and Savings}

Table ES-1 summarizes estimated investment and savings for GSA-owned inventory within the scope of the Smart Buildings initiative. This analysis shows that Smart Building improvements could:

- Reduce energy costs by $4 \%$, from $\$ 1.93 / \mathrm{ft}^{2}-\mathrm{yr}$ to $\$ 1.85 / \mathrm{ft}^{2}-\mathrm{yr}$

- Reduce operating costs by an estimated $12 \%$, from roughly $\$ 3.70 / \mathrm{ft}^{2}-\mathrm{yr}$ to $\$ 3.26 / \mathrm{ft}^{2}-\mathrm{yr}$

This will require:

- An investment in the core building systems of $\$ 0.35 / \mathrm{ft}^{2}$

- An investment in systems integration of $\$ 0.22 / \mathrm{ft}^{2}$

- An investment in enterprise operations of $\$ 0.29 / \mathrm{ft}^{2}$

Estimates are based on GSA's FY2008 nation-wide average of $\$ 1.93$ per square foot for energy costs. GSA estimated operating cost at $\$ 3.70$ per square foot per year including monitoring and management by facility managers and building operators/engineers, maintenance, and cleaning.

Table ES-1: Estimated Savings due to Smart Building Improvements

\begin{tabular}{|c|c|c|c|c|}
\hline Category / Strategy & $\begin{array}{c}\text { Estimated } \\
\text { Investment } \\
\left(\$ / \mathrm{ft}^{2}\right)\end{array}$ & $\begin{array}{c}\text { Current } \\
\text { Operating } \\
\text { Cost } \\
\left(\$ / \mathrm{ft}^{2} / \text { year }\right)\end{array}$ & $\begin{array}{l}\text { Projected } \\
\text { Operating } \\
\text { Cost } \\
\left(\$ / \mathrm{ft}^{2} / \text { year }\right)\end{array}$ & $\begin{array}{l}\text { Estimated } \\
\text { Savings } \\
\text { (\$/ft } / \mathrm{ft}^{2} / \text { year) }\end{array}$ \\
\hline Energy & & $\$ 1.93$ & $\$ 1.85$ & $\$ 0.08$ \\
\hline Operations & & $\$ 3.70$ & $\$ 3.26$ & $\$ 0.44$ \\
\hline High performance building core & $\$ 0.35$ & & & $\$ 0.07$ \\
\hline Systems integration & $\$ 0.22$ & & & $\$ 0.22$ \\
\hline Enterprise operations & $\$ 0.29$ & & & $\$ 0.22$ \\
\hline Total (per square foot) & $\$ 0.86$ & $\$ 5.63$ & $\$ 5.11$ & $\$ 0.52$ \\
\hline
\end{tabular}

Table ES-2 shows the simple payback for three scopes of benefits and savings:

- Energy only (improved energy efficiency)

- Operations only (enhanced operational effectiveness)

- Energy and operations benefits combined 
Table ES-2: Estimated Investment, Savings, and Simple Payback

\begin{tabular}{|c|c|c|c|}
\hline $\begin{array}{c}\text { Quantity } \\
\text { Scope of Benefits }\end{array}$ & Investment & Savings & Simple Payback \\
\hline \multicolumn{4}{|l|}{ Energy benefits only } \\
\hline$\$$ per square foot & $\$ 0.86$ & $\$ 0.08$ & \multirow[t]{2}{*}{11.2 years } \\
\hline Total portfolio in scope & $\$ 130$ million & \$12 million & \\
\hline \multicolumn{4}{|l|}{ Operations benefits only } \\
\hline$\$$ per square foot & $\$ 0.86$ & $\$ 0.44$ & \multirow[t]{2}{*}{1.9 years } \\
\hline Total portfolio in scope & $\$ 130$ million & $\$ 67$ million & \\
\hline \multicolumn{4}{|c|}{ Combined energy and operations benefits } \\
\hline$\$$ per square foot & $\$ 0.86$ & $\$ 0.52$ & \multirow[t]{2}{*}{1.7 years } \\
\hline Total portfolio in scope & $\$ 130$ million & \$78 million & \\
\hline
\end{tabular}

Figure ES-2 shows the operating costs before and after the investment in Smart Buildings.

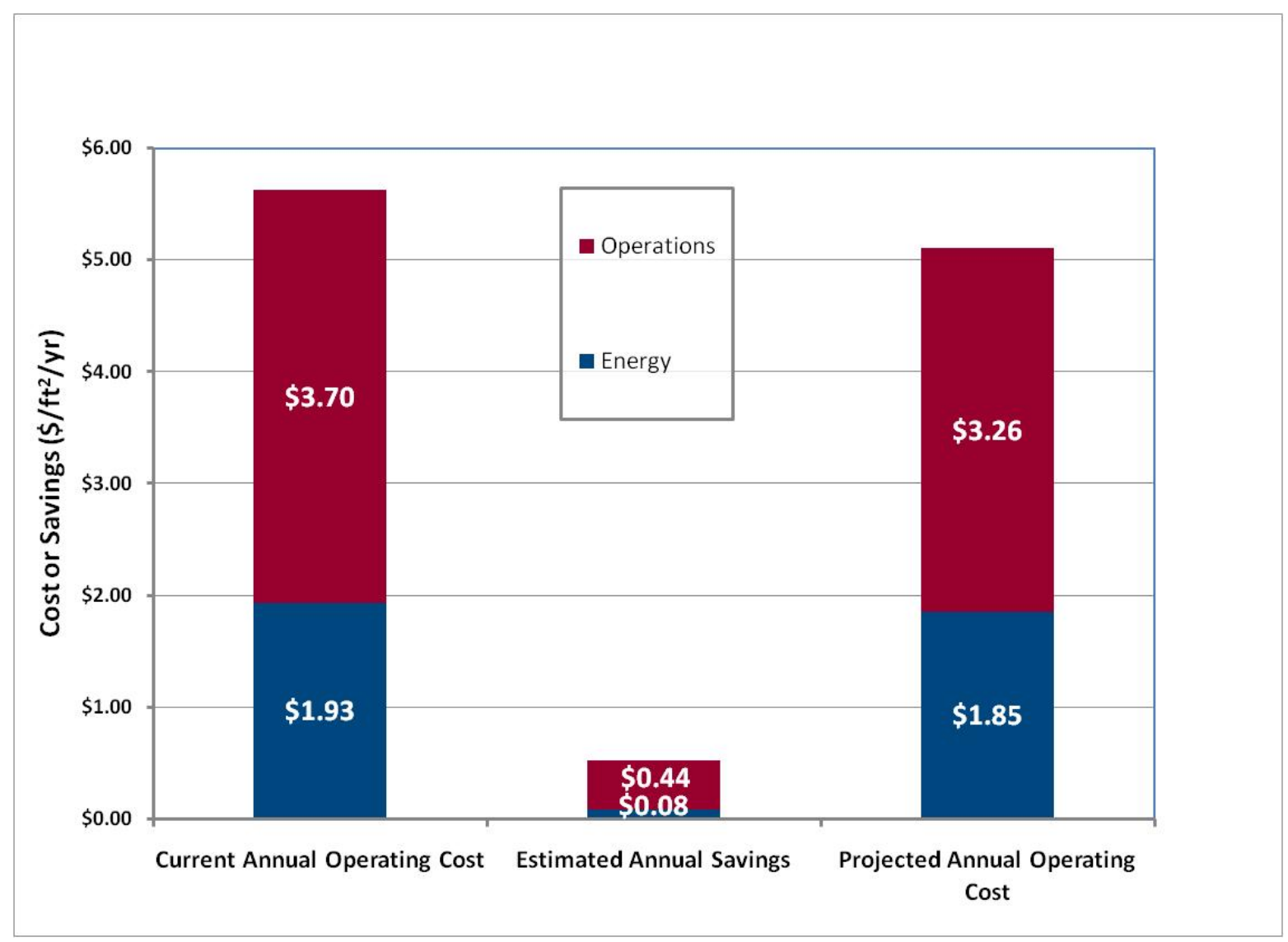

Figure ES-2: Current and Projected Operating Costs 


\section{GSA}

Figure ES-2 shows that while the greatest cost is the investment to network the core building systems, the bulk of the savings occurs in operational benefits of systems integration and enterprise management. This investment in Smart Building strategies across the GSA portfolio of buildings would have a simple payback of less than five years.

Scalability. Figure ES-3 shows how the Smart Buildings business case scales as a function of the impacted building floor space.

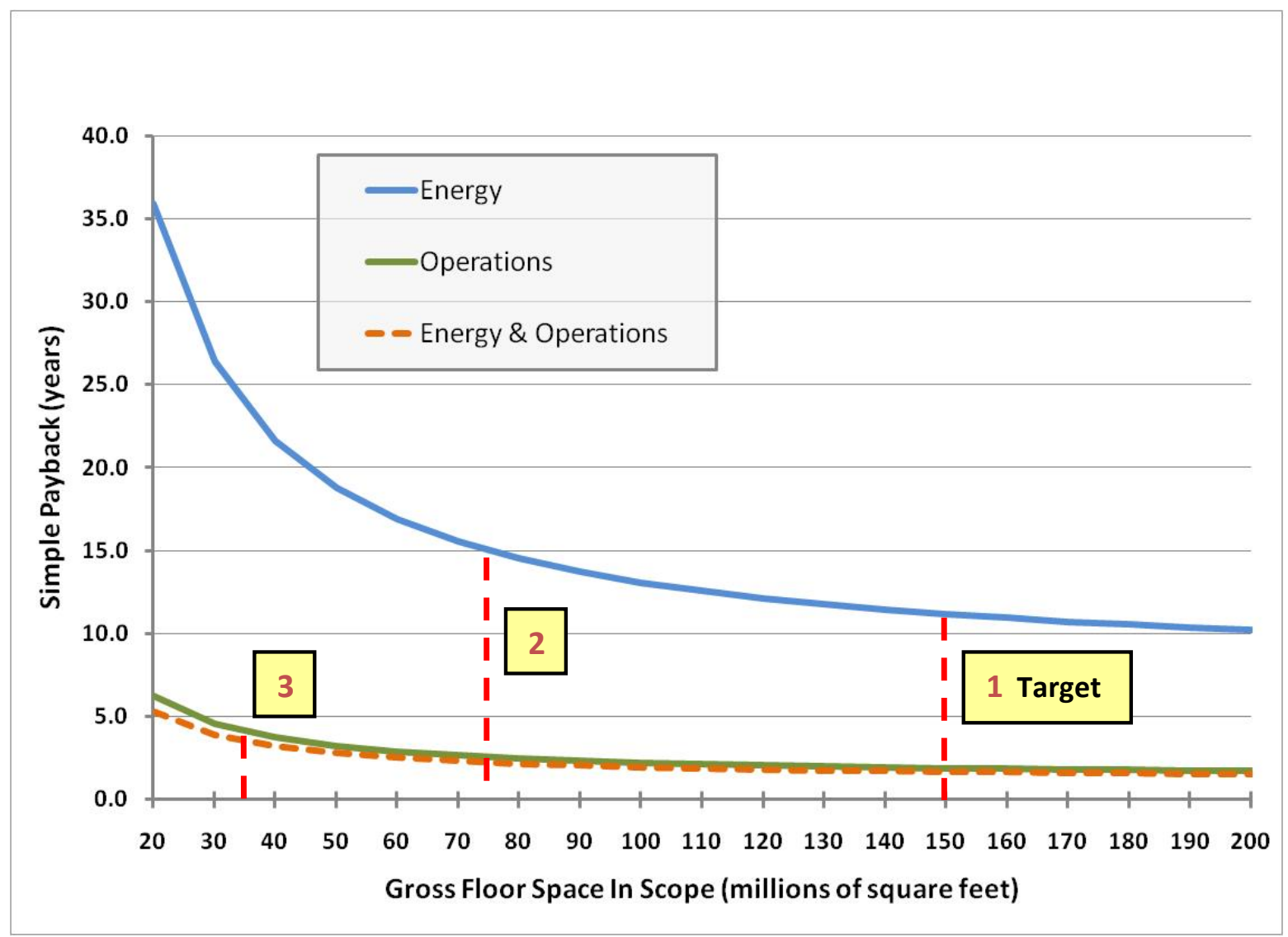

Figure ES-3: Scalability of Smart Buildings

These observations apply (per the corresponding numbered labels):

1. The nominal scope of the analysis is 300 buildings or 150 million SF.

2. Simple payback and other financials are not very sensitive to scope above 75 million square feet. However, reducing the scope below 75 million square feet yields diminishing returns for energy savings alone.

3. When combined energy and operations benefits are considered, Smart Buildings' financial scalability extends all the way down to 20 million 
square feet, with diminishing returns taking hold at about 35 million square feet.

The Smart Buildings business case appears to be fairly scalable except perhaps on a very small scale where the investment in the enterprise management component is large relative to the benefits. However, the high performance building control core, and systems integration layers appear to scale well across the entire range of gross floor space.

\section{Part 4. Recommended Action Plan}

We developed a five-year action plan that recommends steps to achieve the goals of a Smart Building initiative. The five-year action plan is intended to work in concert with public building renewal under the American Recovery and Reinvestment Act, and is based on the scope and depth discussed in prior sections of 150 million square feet and 300 buildings.

The overall strategy for the Action Plan has three steps:

1. Planning

2. Pilots

3. Broad Deployment

To aid in the development of the Recommended Action Plan we developed a scenario analysis for the initial deployment of the demonstration pilots. These scenarios look at different numbers, types, locations and size of the pilots, present arguments for and against each scenario, and makes initial recommendations for each.

The action plan is detailed in Table ES-3 and illustrated by Figure ES-4 below. 
Table ES-3: Recommended Action Plan

\begin{tabular}{|c|c|c|}
\hline \multicolumn{2}{|c|}{ Year } & Activity \\
\hline 1 & 2009 & $\begin{array}{l}\text { - Incorporate integration language and network requirements into the } \\
\text { revised P100 and Smart Building Design Guide } \\
\text { - } \quad \text { Issue revised P100 and Smart Building Design Guide } \\
\text { buildings begins under the Recovery Act, and work continues } \\
\text { through } 2012 \\
\text { - Include Smart Buildings work in selected projects as pilots, and } \\
\text { based on experience, adjust and expand to all GSA projects over the } \\
\text { next } 18 \text { months. } \\
\text { - Conduct Building Operations Centers Research project } \\
\quad \text { Review existing sites (GemNet, Boston Properties, Cisco, } \\
\quad \text { State of Missouri, University of NC, etc.) } \\
\circ \quad \text { Review national energy aggregation program (EUAS) } \\
\circ \quad \text { Compile best practices and processes } \\
\quad \text { Identify key software elements, protocols and standards, } \\
\quad \text { potential suppliers } \\
\circ \quad \text { Develop a plan to test and deploy broadly within GSA } \\
\text { - Identify regions and sites to participate in pilots } \\
\text { Issue RFP for pilot software and systems } \\
\text { Begin pilot projects }\end{array}$ \\
\hline 2 & 2010 & 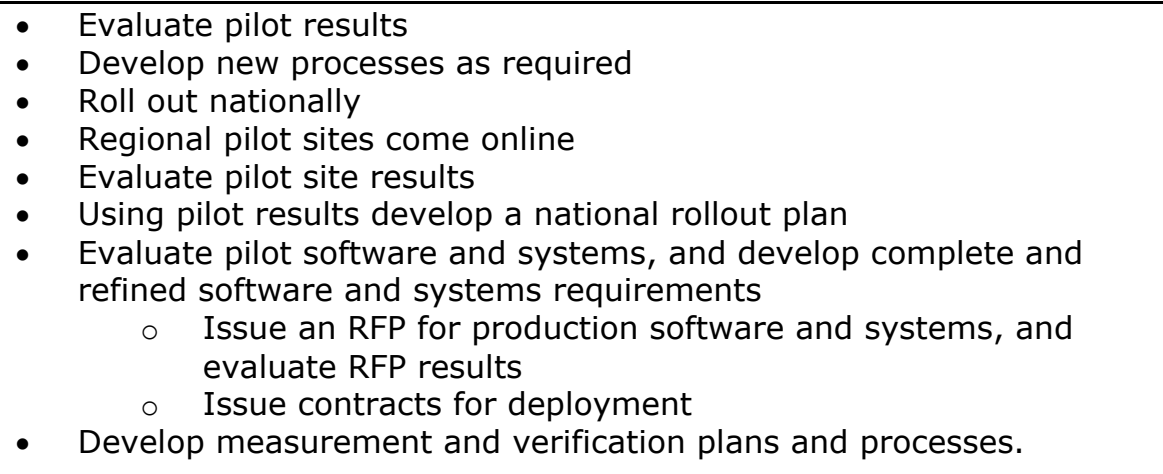 \\
\hline 3 & 2011 & $\begin{array}{l}\text { - Staff development and training } \\
\text { - } \quad \text { Continued evaluation, adjustment, and subsequent deployment of } \\
\text { piloted concepts, technologies, and processes. } \\
\text { - } \quad \text { Retrospective evaluation of projects completed with lessons learned } \\
\text { to be incorporated in current and future projects. } \\
\text { - Measurement and verification of projects completed. } \\
\text { - Begin broad national deployment }\end{array}$ \\
\hline 4-5 & $\begin{array}{c}2012 \\
\text { to } \\
2013\end{array}$ & $\begin{array}{l}\text { - } \quad \text { Continued measurement and verification. } \\
\text { - } \quad \text { Continued retrospective evaluation and adjustment. } \\
\text { - Broad deployment of all programs. }\end{array}$ \\
\hline
\end{tabular}



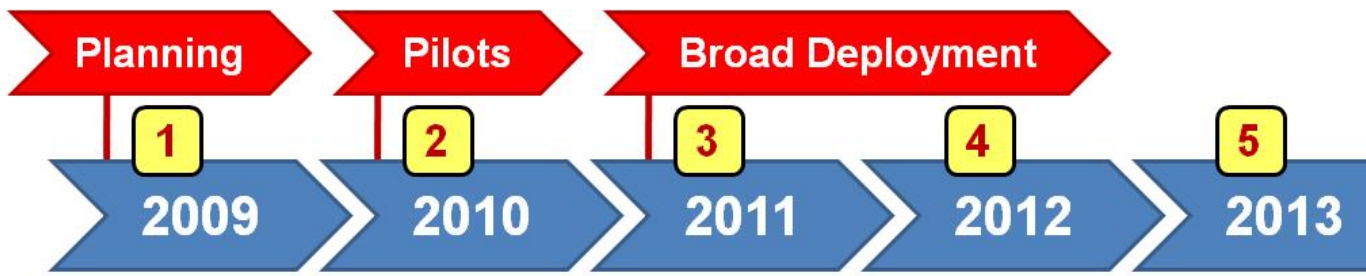

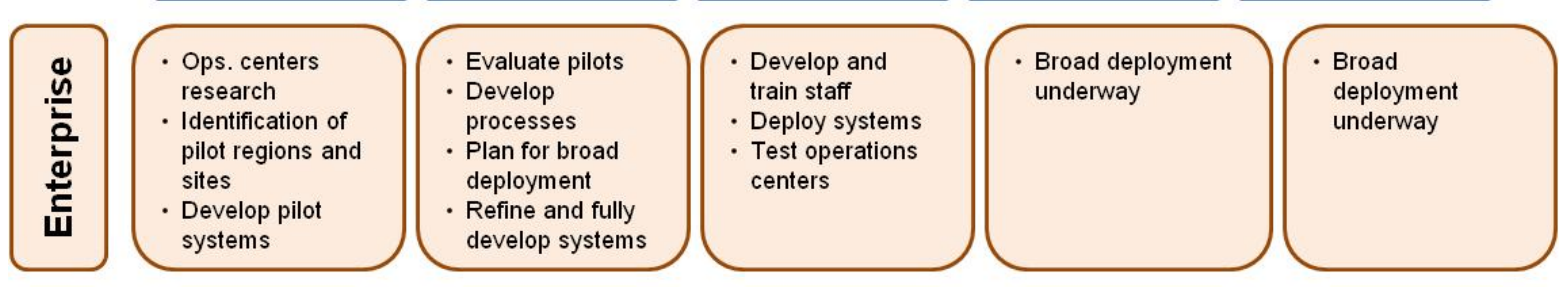

\begin{tabular}{|c|c|c|c|c|c|}
\hline 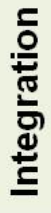 & $\begin{array}{l}\text { - Incorporate into } \\
\text { P100 and design } \\
\text { guide } \\
\text { - Include this } \\
\text { scope in selected } \\
\text { pilot building } \\
\text { projects }\end{array}$ & $\begin{array}{l}\text { - Evaluate pilots } \\
\text { - Develop } \\
\text { standard } \\
\text { processes } \\
\text { - Plan for broad } \\
\text { deployment } \\
\text { - Conduct training }\end{array}$ & $\begin{array}{l}\text { Broad } \\
\text { deployment } \\
\text { underway }\end{array}$ & $\begin{array}{l}\text { - Broad deployment } \\
\text { underway }\end{array}$ & $\begin{array}{l}\text { Broad } \\
\text { deployment } \\
\text { underway }\end{array}$ \\
\hline $\begin{array}{l}\frac{0}{0} \\
0 \\
0 \\
0 \\
0 \\
\mathbf{n}\end{array}$ & $\begin{array}{l}\text { - Revised P100 } \\
\text { and design guide } \\
\text { - Included in } \\
\text { design for } \\
\text { upgrades and } \\
\text { retrofits under } \\
\text { Recovery Act }\end{array}$ & $\begin{array}{l}\text { - Apply in building } \\
\text { projects under } \\
\text { ARRA } \\
\text { - Broad } \\
\text { deployment } \\
\text { underway }\end{array}$ & $\begin{array}{l}\text { Broad } \\
\text { deployment } \\
\text { underway }\end{array}$ & $\begin{array}{l}\text { - Broad deployment } \\
\text { underway }\end{array}$ & $\begin{array}{l}\text { Broad } \\
\text { deployment } \\
\text { underway }\end{array}$ \\
\hline
\end{tabular}

Figure ES-4: Action Plan 


\section{Part 1. Background}

\subsection{Introduction}

GSA has been a pioneer in using Smart Building technologies but it has yet to achieve the full benefits of an integrated, enterprise-wide Smart Building strategy. In July 2008, GSA developed an initial briefing memorandum that identified five actions for a Smart Buildings feasibility study:

1. Identify and cluster the major building systems under consideration for a Smart Buildings initiative

2. Identify GSA priorities for these clusters

3. Plan for future adoption of Smart Building strategies by identifying compatible hardware

4. Develop a framework for implementing and testing Smart Building strategies and converged networks

5. Document relevant GSA and industry initiatives in this arena

Based on this briefing memorandum, PBS and FAS retained consultants from Lawrence Berkeley National Laboratory, Noblis, and the Building Intelligence Group to evaluate the potential for Smart Buildings within GSA, and to develop this report. The project has included extensive interviews with GSA staff (See Appendix A), a review of existing GSA standards and documents, and an examination of relevant GSA and industry initiatives.

\subsection{Project Goals}

Based on interviews with GSA staff and a review of GSA standards and documents, the project team focused on four goals for evaluating how Smart Building technology can benefit GSA:

1. Achieve Energy Efficiency Mandates. Use Smart Building technology as a tool to meet EISA 2007 and EO 13423 goals for energy efficiency.

2. Enhance Property Management. Deploy enterprise tools for improved Operations and Maintenance (O\&M) performance and verification.

3. Implement Network as the Fourth Utility. Utilize a converged broadband network to support Smart Building systems and provide GSA clients with connectivity for voice, data and video.

4. Enhance Safety and Security. Harmonize Physical Access Control Systems (PACS) with Smart Building Systems.

\subsection{What is a Smart Building?}

A "Smart Building" integrates major building systems onto a common network and uses shared information and function of these systems to improve energy efficiency, operational effectiveness, and occupant satisfaction. While the concept of a Smart Building has been promoted since the late 1980s, it is only recently that ongoing cost reductions in technology, broad deployment of networks, and the development and 
widespread adoption of open standards for building system communications protocols have made such projects viable.

A Smart Building has three levels of optimization and integration (Figure 1-1), starting with a base of optimized core systems, which support a middle tier of converged networks and systems integration, which in turn enables a top level of enterprise integration and optimized business practices across multiple buildings.

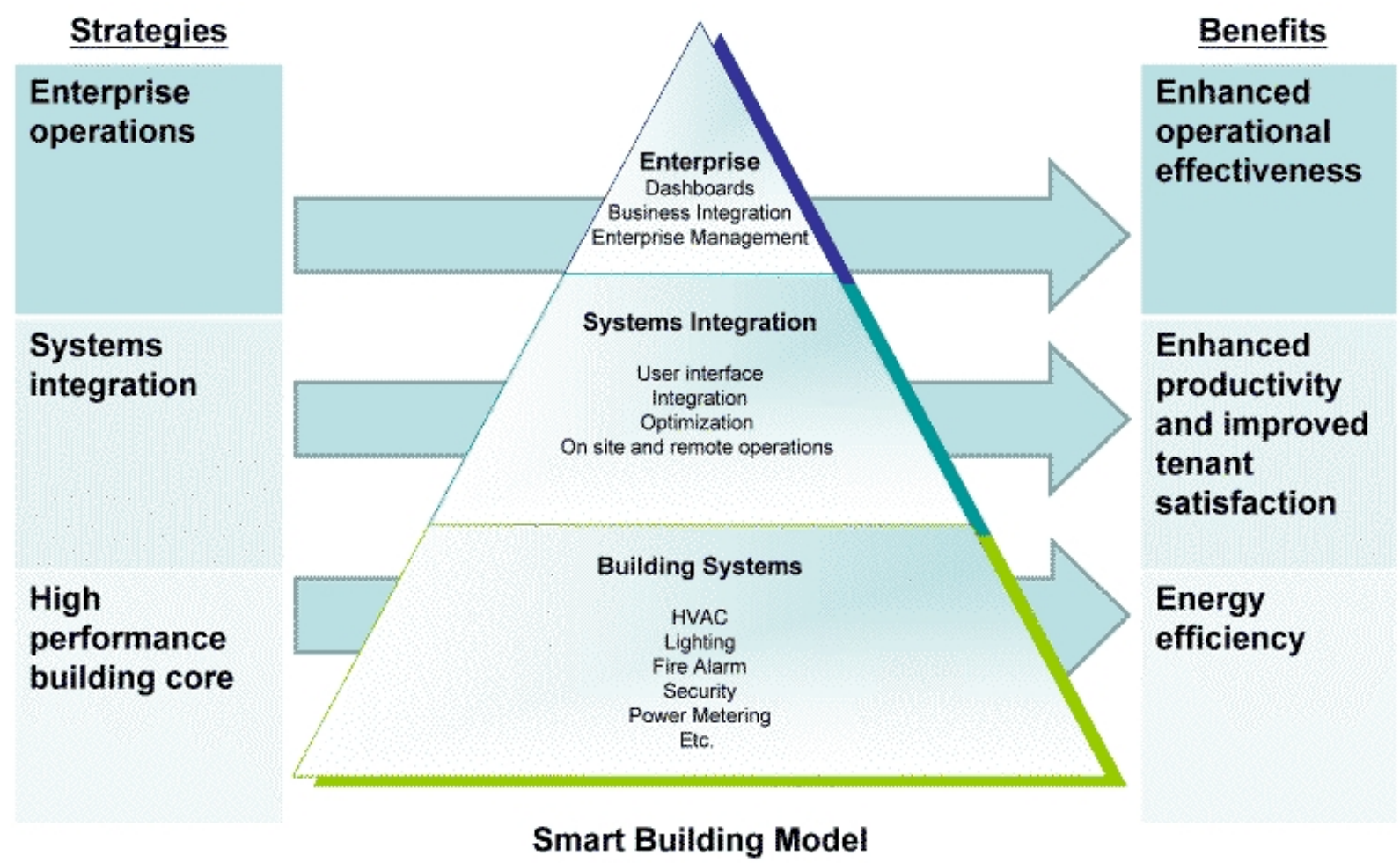

Figure 1-1: Model of the Hierarchy of Smart Building Strategies

High Performance Building Core at the base level optimizes the performance of individual building systems, e.g., HVAC, lighting, fire alarm, security, power metering, networks, etc. For example, performance improves through fault detection, continuous commissioning, and real time performance monitoring. The optimization goes beyond GSA's current P-100 standards and typical building automation systems.

A key element of the High Performance Building Core is a shared building network infrastructure that supports all building systems and enables these systems to communicate with each other and the outside world. This base network includes vertical wiring that distributes building systems traffic over an integrated IP infrastructure. Appendix E illustrates this network infrastructure. All of the elements of the High Performance Building Core are described in more detail in Appendix B. 
Systems Integration, at the second level, takes the relevant systems that have been optimized in level one and integrates them onto a converged network to improve monitoring and control, better performance, increase tenant satisfaction, and reduce cost of network installation and maintenance through:

- Integrated building systems that share information using open standards, enhancing overall functionality.

- Web-based monitoring, which allows for improved control and management of multiple systems within a building and/or across multiple buildings.

- Portals and dashboards, which provide real-time information and analysis for both building occupants and management.

- Integration of multiple building systems, which provides operators with feedback needed to optimize personal comfort and building security.

The vertical network infrastructure element of the core is expandable to provide a converged broadband network for building systems, voice over IP, video and data. Such convergence may eliminate the cost and confusion of multiple proprietary networks, allows customers to plug in phones and/or computers and start working seamlessly upon move in, and fosters competition from multiple telecom/datacom services, allowing selection of best-in-class offerings on a service by service basis.

Enterprise Management, at the third level, centralizes facility information, and provides staff with tools to more effectively channel tenant feedback and provide property management. The benefits achieved in individual buildings at the second level are further enhanced at this level through:

- Web-based monitoring, which allows for improved control and management of multiple systems within a building and across multiple buildings.

- Portals and dashboards, which provide real-time information and analysis for both building occupants and management.

- Enterprise integration, i.e. the integration of benchmarked information and business applications across buildings.

- Pervasive energy management with distribution of energy information and facilitation of energy management practices locally, regionally, and nationally.

- Support for disaster management and operational continuity systems and processes.

Enterprise Management is widely used today by organizations that operate large property portfolios. Some notable examples of building owners who have realized significant benefits from Smart Building strategies include:

- State of Missouri: Developed a central operations center to monitor and manage the energy usage and maintenance issues for over 800 state buildings. This project has resulted in estimated savings of $\$ 30$ million per 
year and a simple payback of less than 2 years through savings in operations, service, and energy.

- University of Michigan: Monitors all buildings on campus from a central location. The University uses analytic software to evaluate the performance of buildings that have been recently recommissioned. Through continuous analysis and feedback, the University discovered and resolved previously unknown issues, further reducing energy costs by $10-15 \%$.

- Wal-Mart: Monitors over 4,000 properties from a central location and can readily diagnose both comfort and service issues. New stores that utilize Smart Building controls use $20-40 \%$ less energy than older stores.

\subsection{What has been GSA's involvement in Smart Buildings?}

GSA has been an early adopter of many of key elements of Smart Buildings design. Some examples of GSA's Smart Building experience include:

- Optimizing Core Systems (level 1), current P-100 Standards require a sophisticated lighting control system and building automation systems for HVAC system control that conform to open standards and provide optimization, including resetting temperatures and pressures.

- Systems Integration (level 2), current standards require limited integration for monitoring but do not allow shared control across systems such as HVAC and Lighting. However, projects such as the Bolling Federal Building retrofit have taken this integration further and earned industry recognition for using a middleware package that provides consistent operations view with open procurement of systems, and improved performance.

- Enterprise Management (level 3), some GSA regions have been early adopters of enterprise management. For example, the Pacific Rim Region's GemNet system has connected more than 28 buildings for centralized monitoring since the late 1990s. The Advanced Metering Strategic Plan Initiative (SAPI) is another example that allows for real time monitoring and historical analysis of energy consumption to establish performance trends and document the success of efficiency improvement efforts.

These and other projects represent GSA's accomplishments and innovation thus far, but GSA could achieve significant additional benefits with a broad, integrated, enterprise management solution. 


\subsection{How will Smart Buildings compliment efforts funded by the Recovery Act?}

\section{Buildings}

Based on GSA programs to renew and renovate public buildings as part of the American Reinvestment and Recovery Act, the following assumptions apply to the Smart Buildings initiative:

- The scope will include 250 to 300 buildings:

- These facilities are distributed across all regions

- 60 to 80 projects are large R\&A (repair and alteration)

- 200 projects are identified as the worst energy performers in the GSA owned portfolio

- The estimated scope is 150 million gross square feet ( $85 \%$ of the GSA owned floor space).

- As a general guideline, buildings larger than 50,000 square feet are Smart Building candidates, while buildings under 20,000 square feet are not.

\section{Scope}

- For buildings in scope, it is assumed that the High Performance Building Core will be put in place as part of work funded by the American Reinvestment and Recovery Act.

- The 250-300 buildings within the Smart Buildings program scope are assumed to have the High Performance Building Core in place as a foundation for Smart Building integration.

- Table 1-1 below summarizes what is covered by GSA plans in accordance with the American Reinvestment and Recovery Act, and what is included in Smart Buildings, respectively. 
Table 1-1: Smart Buildings Scope

\begin{tabular}{|c|c|}
\hline $\begin{array}{c}\text { GSA Plans in Accordance with } \\
\text { the American Reinvestment and } \\
\text { Recovery Act }\end{array}$ & Smart Buildings \\
\hline 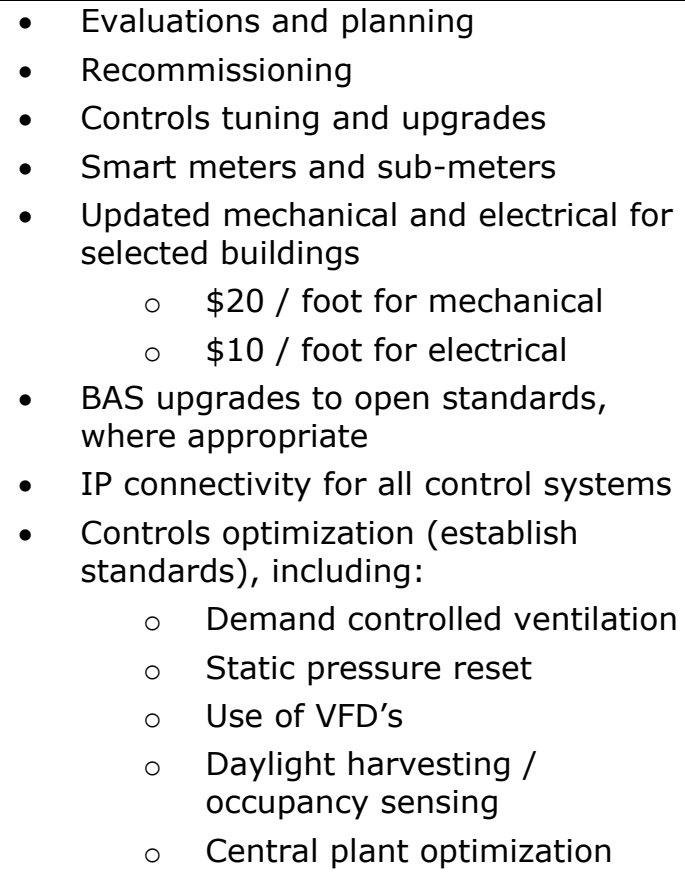 & $\begin{array}{l}\text { - IP network for building systems } \\
\circ \quad \text { Option to expand for tenants } \\
\text { and associated services } \\
\text { - } \quad \text { Systems integration } \\
\circ \quad \text { IP enabling all control systems } \\
\circ \quad \text { Middleware application } \\
\text { - Enterprise management and } \\
\text { operations } \\
\circ \quad \text { Systems and software } \\
\circ \quad \text { Operations centers } \\
\end{array}$ \\
\hline
\end{tabular}

\subsection{Why would GSA pursue Smart Buildings?}

We examine three additional benefits GSA can achieve from Smart Building strategies:

- Improved energy efficiency and energy savings

- Enhanced operational effectiveness

- Increased tenant satisfaction

\section{Improved Energy Efficiency}

GSA facilities are, in general, significantly more energy efficient than their commercial counterparts, due to long standing programs for improving energy efficiency. This makes new mandates for improved energy efficiency more difficult to achieve because the "low hanging fruit," such as lighting upgrades and simple system improvements, have already happened. A Smart Buildings program can further reduce energy usage based on ongoing measurement and verification of energy usage with a goal of continuous improvement by using four approaches:

1. Optimization: These are automated algorithms that allow systems to operate more efficiently while still providing occupant comfort. Examples of these algorithms include chiller plant optimization, static pressure reset, and 
demand controlled ventilation. In each case, control systems are able to use information from the building to operate in a more energy efficient manner.

2. Occupancy-Based Control: Essentially this strategy uses energy only as necessary for building occupants. A Smart Building can use information from systems-such as occupancy sensors, physical access control systems, video cameras, and scheduling software-to minimize energy usage in spaces that are not occupied.

3. Demand Response: This strategy reduces energy costs via lower utility rates and credits. Real time connections between utilities and Smart Buildings enable load reduction to better match utility load profiles.

4. Operational Tools and Analytics: Tools that provide better visibility into building systems - both on site and from remote operations centers-help building owners evaluate and assess building performance. These tools also make it easier to identify opportunities for reducing energy costs.

\section{Enhanced Operational Effectiveness}

Smart Buildings provide tools that dramatically enhance operational effectiveness. These tools provide additional information and diagnostics so operations can dispatch the correct technician, with the correct tools and parts, to resolve an issue in one visit. Because GSA typically outsources building operations, the use of these tools should result in reduced contract costs while also giving GSA a management dashboard for reviewing and evaluating operations contractor performance. Some commonly deployed tools are:

1. The automatic generation of work orders based on system alarms.

2. Handheld tools (such as a smart phone or PDA) that allow operations staff to readily respond to problems from any location.

A converged network also enhances operational effectiveness through improved building wiring and inventory management. With a GSA-provided common building wiring infrastructure, agencies would no longer install vertical wiring in a piecemeal, ad hoc fashion during the course of building occupancy, resulting in less congested telecom closets and building conduits along with cost savings to the Federal Government.

\section{Increased Tenant Satisfaction}

A Smart Building with a GSA-provided common building wiring infrastructure will increase tenant satisfaction by improving upon the current tenant experiences related to telecom and datacom services:

1. Reduced order-to-service-commissioning interval. In today's federal marketplace the longest duration activity associated with a telecom service order is ensuring that vertical building wiring is in place and connected to carrier facilities. A preinstalled building wiring system will reduce the time needed for service commissioning.

2. Reduced adverse effects of service provider "lock-in". In the federal marketplace, the costs associated with telecom and datacom 
transitions (i.e. switching suppliers) are significant due to the inflexibility of traditional wiring systems. When the costs of switching from one telecom supplier to another are substantial, customers become "locked-in" to their choice of supplier, which typically results in paying more than average market prices during the full term of contract. Smart Buildings employ flexible vertical wiring, which significantly reduces the cost of switching service providers.

3. Increased choices for various telecom and datacom services. Greater carrier selection-coupled with low switching costs-will allow agencies to choose best-in-class or niche offerings on a service-by-service basis. In contrast, federal agencies usually tend to select a single provider that provides the best "basket of services" offer because selecting more than one supplier would require duplicate inside wiring.

4. Improved Tenant Productivity. While difficult to quantify, Smart Building strategies have the potential to improve tenant productivity and reduce operating cost. For example, Smart Buildings can provide tenants with improved comfort as well as after-hour access to an office environment that is conditioned only where they work. Flexible vertical wiring supports Voice over IP (VoIP), which in turn supports the 'follow me' telephone service needed to fully implement mobile workplace strategies adapted to contemporary work styles.

\subsection{What are the Smart Building challenges?}

In general, Smart Building technology has matured over the past decade. Systems following open standards-such as BACnet, LonTalk, and Modbus-are readily available from a broad range of major vendors. Also readily available are converged networks, network-enabled controls, and "middleware" software platforms that allow for integration and simplified use through web page displays of building systems.

While significant progress has been made in the development of the required technologies and standards facilitating Smart Buildings, significant challenges remain. Four key process challenges identified by industry leaders are:

- Integrated Project Planning: Making the investment in a Smart Building requires evaluation of anticipated ROI. The tools to provide this analysis are often not available to project teams. As a result, Smart Building attributes are not adequately evaluated at multiple levels during the design and delivery process, resulting in poor system selection and value engineering decisions.

- Integrated Design Process: Designing a new Smart Building, or retrofitting an existing building, requires an integrated design approach that includes expertise in building systems, controls, business systems, and networking. These skills typically require the use of a specialized consultant. 
- Competent Contractors and Integrators: The skill level of systems integrators varies greatly. A comprehensive training and certification program would facilitate the success of Smart Buildings.

- Qualified Operators: Operating a Smart Building efficiently requires developing new processes and a comfort level with the use of technology. As with contractors and systems integrators, a comprehensive training and certification program would help to establish operator qualifications for Smart Buildings. In addition, operations teams may require retraining or the addition of new skills, such as IT support.

\subsection{What are the GSA specific challenges?}

In addition to the challenges faced by all building owners and operators, GSA should consider several agency-specific challenges in pursuing a Smart Buildings program.

1. Unprecedented scope and scale. The Smart Buildings initiative-in combination with efforts funded by the American Reinvestment and Recovery Act-comprises one of the largest programs in the history of the United States to comprehensively renovate and retrofit existing buildings. Furthermore, the time frame in which this is expected to occur is relatively short for such a program. With this very ambitious and unprecedented program comes the challenge of managing and fulfilling the plan in the time allotted.

2. Complexity may overwhelm operations and maintenance resources. During staff interviews, many questioned whether GSA should integrate multiple systems as in a smart building. One staff member summarized the concern of the operations community best:

"Too much complexity, or too many systems bundled together, will overwhelm our building contractors operations and maintenance resources. We have great difficulty getting effective operation of our existing building fire protection, energy management systems, and security systems, now. We do not wish to see these systems conflicting with each other and creating problems and issues."

These and similar concerns will need to be addressed through education, pilot demonstrations, and other strategies.

3. Current P-100 standards prohibit cross system control or optimization. Current standards also do not require advanced control algorithms, such as demand controlled ventilation.

4. Existing buildings may need extensive upgrades. Many existing GSA buildings conform to earlier design standards but not to the current P-100 design standards and they may have older, proprietary, non-optimized systems installed.

5. Existing challenges with operations contractors' performance and turnover may impact GSA's ability to maintain Smart Building performance.

6. To achieve the enterprise level benefit of smart buildings, GSA will need to adopt a national standard for Computerized Maintenance Management Systems (CMMS). 
The recommendations that follow are designed to address these challenges, drawing on lessons learned from industry as well as the experience and expertise of GSA staff. A key component of the following recommendations is the need for continuous evaluation and improvement of the Smart Building strategies, starting with the initial pilot projects and continuing through the proposed five-year roll-out. 


\section{Part 2. Priority Actions}

\subsection{Smart Building Attributes for GSA Buildings}

Two of the initial directives for this project were to "Identify and cluster the major building system under consideration for a Smart Building initiative" and "Identify the GSA priorities for these clusters." We took the following steps to develop the recommended strategies:

1. Evaluated the list of 31 potential elements provided by GSA (Figure 2-1).

\begin{tabular}{|c|c|}
\hline & Camera \\
\hline 2 & Dampers \\
\hline 3 & Indoor air quality services \\
\hline 7 & Air filters \\
\hline 5 & Air handling unit coolers \\
\hline 6 & Cooling coils \\
\hline 7 & Fans \\
\hline 8 & Exhaust fans \\
\hline 9 & Smoke detectors \\
\hline 10 & Cooling towers \\
\hline 11 & Elevators \\
\hline 12 & Zone control panels \\
\hline 13 & Lighting \\
\hline 14 & Heating units \\
\hline 15 & Halon system \\
\hline 16 & VAV units \\
\hline 17 & Diffusers \\
\hline 18 & Intrusion detectors \\
\hline & Card readers \\
\hline
\end{tabular}

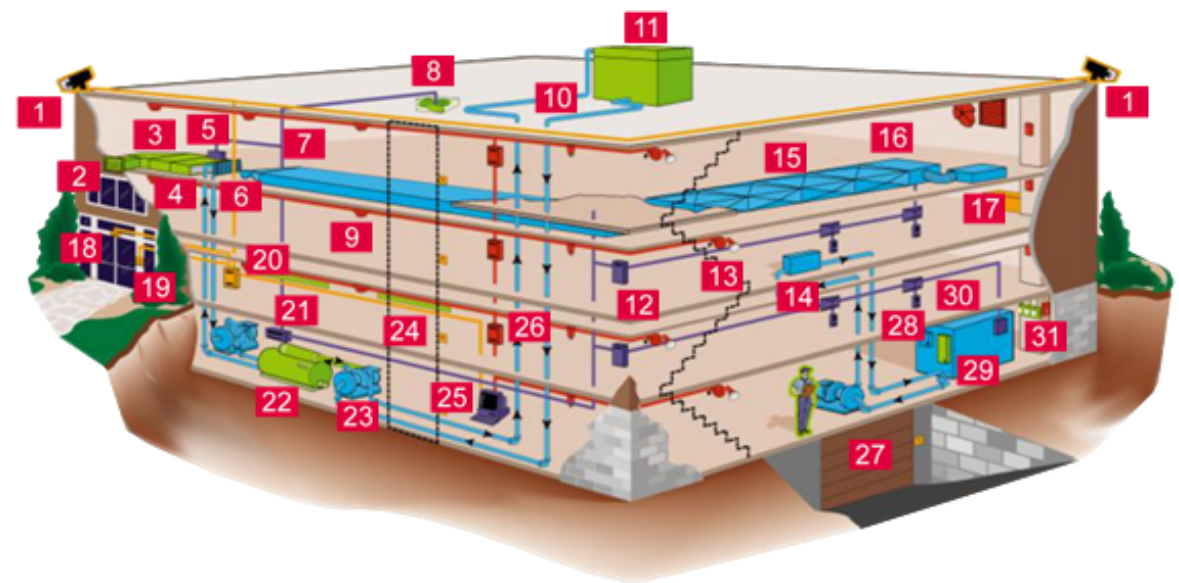

20 Access management controllers
21 Chemical water control
22 Chillers and boilers
23 Pumps
24 Computer room air handlers
25 Operators station
26 Fire alarm panels

Figure 2-1: Smart Building Elements (Diagram from BAE Systems)

2. Clustered the elements using input from GSA staff interviews into logical building systems by priority, goal, Construction Specification Institute (CSI) classification, and GSA P-100 sections as shown in Table 2-1. The highest priority systems achieve energy savings-HVAC accounts for roughly $40 \%$ of total current energy use and lighting accounts for roughly $28 \%$ of total current energy use. The next cluster is energy metering-not an end use in itself but an important tool for analyzing and controlling energy use.

3. Evaluated each of the resulting systems for its potential to meet our project goals. For example, optimizing and integrating energy intensive systems (e.g., Lights and HVAC) are high priorities in accomplishing goal \#1 "Achieve Energy 
Efficiency Mandates". Systems that did not readily support these goals were either not included in the recommended actions or given lower priorities.

4. Further evaluated the systems that support the project goals, estimated the cost and benefits of optimizing and integrating these systems as part of the financial analysis, and developed the recommendations. We continued with an analysis beyond the segmentation and grouping in order to provide adequate detail for the strategies to connect and optimize these systems and the processes that achieve the desired results. The details are in Appendix B.

Table 2-1: Systems, Cross References and Goals in Priority Order

\begin{tabular}{|l|l|l|l|l|}
\hline $\begin{array}{l}\text { System } \\
\text { (by priority) }\end{array}$ & $\begin{array}{l}\text { CSI 1995 } \\
\text { Section }\end{array}$ & $\begin{array}{l}\text { P-100 } \\
\text { Section }\end{array}$ & BAE ID & Goal(s) \\
\hline HVAC & 15900 & 5.16 & $\begin{array}{l}2,3,4,5, \\
6,7,8, \\
10,12,14, \\
16,17,21, \\
22,23,28\end{array}$ & Energy Efficiency \\
\hline $\begin{array}{l}\text { Lighting } \\
\text { Control }\end{array}$ & 16000 & 6.8 & 13 & Energy Efficiency \\
\hline $\begin{array}{l}\text { Energy } \\
\text { Metering }\end{array}$ & 16000 & TBD & 31 & $\begin{array}{l}\text { Energy Efficiency, } \\
\text { Operational } \\
\text { Effectiveness }\end{array}$ \\
\hline Fire Alarm & 16000 & 7.9 & 9,26 & $\begin{array}{l}\text { Operational } \\
\text { Effectiveness }\end{array}$ \\
\hline $\begin{array}{l}\text { Access } \\
\text { Control }\end{array}$ & 16000 & 6.16 & $18,19,20$ & Security Enhancement \\
\hline CCTV & 16000 & 6.16 & 1 & 11 \\
\hline Elevators & 14000 & 3 & Not shown & $\begin{array}{l}\text { Operational } \\
\text { Effectiveness }\end{array}$ \\
\hline Generators & 16000 & 6.12 & 15,24 & $\begin{array}{l}\text { Operational } \\
\text { Effectiveness }\end{array}$ \\
\hline Data Center & N/A & TBD & 30 & Security Enhancement \\
\hline Other & N/A & & N/A & \\
\hline
\end{tabular}




\subsection{Smart Building Design and Operation Recommendations}

The following recommendations present strategies for the design and operation of Smart Buildings. Recommendations $1-3$ are based on the "pyramid" model shown earlier in Figure 1-1. The details of these strategies are included in Appendix B. Recommendations 4 and 5 address the different needs of new and existing buildings when implementing a Smart Buildings program.

\section{Recommendation \#1: Deploy a High Performance Building Control Core}

The first step for Smart Building operations is to optimize the individual building systems and enable controls for wider integration between systems:

- Update and optimize HVAC controls

- Update and optimize lighting controls, such as occupancy-based scheduling

- Expand energy metering program

- Evaluate existing vertical network infrastructure

- Enable monitoring of fire and life safety systems

- Enable physical access control systems (PACS)

Central to and included in the High Performance Building Control Core is a vertical network infrastructure to support all building systems. While this network infrastructure may be expandable to a converged network that provides voice, video, and data services to tenants, it is only the basic vertical network infrastructure that is recommended for implementation in Smart Buildings.

This High Performance Building Control Core is anticipated to be deployed in buildings within the scope of this effort as part of the larger public building renewal conducted in accordance with the American Reinvestment and Recovery Act. This core serves as the foundation for Recommendations 2 and 3 that follow.

\section{Recommendation \# 2: Integrate Relevant Building Systems}

The second step is the integration of the relevant building systems. The strategies to be considered for implementation include:

- Integrate monitoring of fire and life safety systems

- Integrate CCTV cameras on converged network

- Implement converged vertical networks

- Implement a "middleware" software solution

- Develop a unified user interface with support for mobile and remote operations access

- Optimize across systems for energy efficiency

- Consider the potential for demand response based on a building's location and the servicing utilities. 


\section{Recommendation \# 3: Develop an Enterprise Management Strategy based on Building Operation Centers}

The third recommended step is development of an Enterprise Management strategy based on a series of centralized Building Operations Centers (BOC). The BOCs would provide a resource for tenant services, operations management, energy analysis, network support, security, and continuity.

There are a number of options for deployment of these centers, including developing them on a regional or national basis. The decision on how BOCs should be implemented is outside the scope of this report. We recommend the following process for developing this implementation plan:

1. Build upon the Advanced Metering Initiative with a focus on collecting energy information and providing near real-time benchmarked energy data.

2. Start with pilot projects in selected regions and then expanding nationally. Data design should allow for both regional as well as national operations and monitoring.

3. Implement new operations processes and tools for:

a. Enterprise energy management extending from existing programs, e.g., SAPI

b. Central alarm monitoring and tracking through systems such as CMMS

c. Tracking of work orders

d. Continuous recommissioning

e. Tools for operations contractor assessment

f. Systems analytics including fault detection and diagnostics

g. Network and IT support

4. Connect buildings to the BOC as they become IP enabled and network support becomes available.

5. Use pilot projects to allocate scope of work for operations centers on a regional and/or national basis.

\section{Recommendation \# 4: Use Integrated Design for All New Buildings}

New buildings represent the easiest opportunities for smart buildings implementation. The basic strategy is to use an integrated design approach for both design and operation. The recommended steps include:

1. Update the $2005 \mathrm{P}-100$ to provide enhancements for both mechanical and electrical areas.

2. Use an integrated design approach that is focused on optimizing all systems and delivering enhanced operations tools. This One-GSA approach will combine the expertise of PBS and FAS.

3. Establish multi-disciplinary leadership roles in the design and implementation process, including a "Building Systems Architect" and/or "Master Systems Integrator". The Building Systems Architect drives the design and delivery of the integrated systems, while the "Master Systems Integrator" may go a step further and provide project management and oversight of implementation. Such roles may be specialized consultants, or another project team member, such as the architect, mechanical or electrical engineer, commissioning agent. 


\section{Recommendation \# 5: Upgrade Existing Buildings Comprehensively}

The Smart Building concept can be readily applied to existing buildings as well as new buildings, and it is in fact likely that existing buildings will comprise the majority, if not all of the building projects undertaken per the Recovery Act. The challenge with existing buildings is that they consist of a broad range of ages, equipment and systems. As a result, systems may need to be upgraded or replaced in order to realize the benefits of this program.

We recommend the following process for existing buildings:

1. Smart Building Audit: Develop a process to assess the condition of the existing buildings addressed as part of public building renewal in accordance with the Recovery Act. This audit could be coordinated with larger scope building assessments but is specifically focused on energy related equipment, systems, and their related control systems. This effort should also be included in all Building Evaluation Reports (BERs)

2. Smart Building Plan: Using the results of the audit, develop a Smart Building plan for each building or group of buildings. This plan should include:
a. Recommended system upgrades, and coordination with overall building renovation and retrofit plans
b. Systems that require complete replacement
c. Recommended network changes and upgrades
d. Recommended infrastructure to support voice, video, and data
e. Installation of middleware software for integration
f. Development of new or enhanced user interface
g. Plans for complete retro-commissioning
h. Calculations of cost including return
i. Required investment
j. Recommended implementation schedule

3. Smart Building Delivery: Utilize the plan, acquire funding and get contracts for design and implementation of the Smart Building project for each building. Delivery can be done using standard contracting, design build, or performance based contracting. In general, as stated previously, much of the building system upgrades will be included in the scope of building work to be completed in accordance with the American Recovery and Reinvestment Act. 


\section{Part 3. Costs, Investment, and Savings}

\subsection{Basic Methodology}

This high level financial analysis estimates the cost and savings associated with implementing Smart Buildings. The method used to perform the analysis consists of six basic steps shown in Figure 3-1.

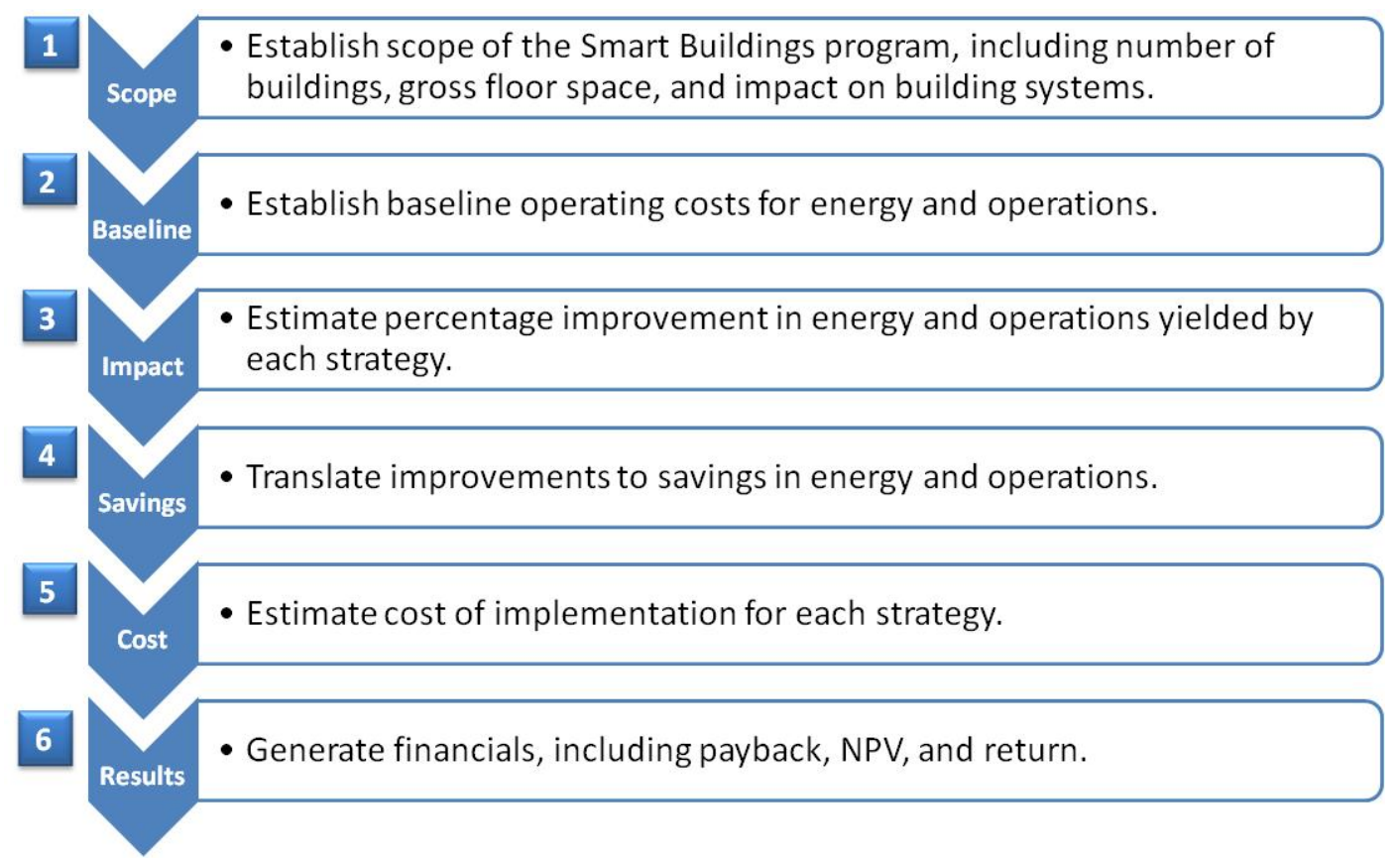

Figure 3-1: Financial Analysis Methodology

The hierarchical Smart Building Model (Figure 1-1) provides a basis for understanding the financials, and illustrates the conceptual relationship between the smart building model, the strategies employed, and the benefits derived.

The optimized building systems that make up the high performance building core provide the foundation for the smart building layers that build upon it, and requires the greatest investment. Systems integration provides the bridge between the high performance building core and enterprise operations. Finally, the enterprise operations build upon the other two layers. While the individual layers may provide some discrete benefits individually, it is the combination of the layers in this hierarchical relationship that maximizes smart building benefits.

While the financial analysis sought to quantify the investment, savings, and return, it must be understood that this is a high level analysis, and the financials for individual building projects must also be addressed on a case-by-case basis. 
Conservative assumptions were used in this financial analysis:

- Estimated energy and operations savings are relatively conservative.

- Energy savings associated with the High Performance Building Control Core, the base layer in the Smart Buildings hierarchy, is not assumed to be a financial benefit of Smart Buildings because it is assumed to be funded by economic stimulus plans. However, the potential energy savings is identified.

- Energy prices are assumed to remain relatively flat and no savings were attributed to expected future increase in energy costs.

- Potential additional energy savings associated with utility programs enabled by Smart Buildings, such as demand response, are identified, but no financial benefit is assumed.

\subsection{Input and Assumptions}

Input and assumptions for this analysis are based on information provided by the GSA. This input includes estimates of energy and operating costs:

- Energy cost for all energy sources is $\$ 1.93$ per square foot per year.

- Operations cost is estimated by the GSA at $\$ 3.70$ per square foot per year including monitoring and management by facility managers and building operators/engineers, maintenance, and cleaning.

In addition, a series of interviews with the Office of High Performance Buildings and the Office of the Chief Architect provided information on the scope of efforts under the American Reinvestment and Recovery Act, and how the Smart Buildings program complements the larger infrastructure renewal effort. The scope in terms of buildings and floor space is as follows:

- Buildings within scope: 250 to 300

- These facilities are distributed across all regions

- 60 to 80 projects are large R\&A (repair and alteration)

- 200 projects will be the worst energy performers in the GSA owned portfolio

- Floor space: 150 million gross square feet or $85 \%$ of GSA owned space.

Retrofits and upgrades to building systems will be divided between the larger infrastructure renewal plans and the Smart Building initiative. The basic assumption is that the High Performance Building Control Core-with the exception of the building system network infrastructure-is included and funded by efforts in accordance with the American Reinvestment and Recovery Act. The network infrastructure element of the core, combined with systems integration and enterprise management, are part of the Smart Buildings scope. Table 3-1 describes this in more detail.

Lastly, the scope and depth of the Smart Buildings program is anticipated to require investment and to yield significant benefit and savings to the GSA. For each of the three hierarchical layers in the Smart Building model, the investment necessary is 
estimated, and the energy and operational savings are projected. Additional details on investment and savings are provided in the subsections that follow, and in Appendices C and D.

Table 3-1: Estimated Smart Building Investment and Savings

\begin{tabular}{|c|c|c|c|c|}
\hline Category / Strategy & $\begin{array}{c}\text { Estimated } \\
\text { Investment } \\
\left(\$ / \mathrm{ft}^{2}\right)\end{array}$ & $\begin{array}{c}\text { Current } \\
\text { Operating } \\
\text { Cost } \\
\left(\$ / \mathrm{ft}^{2} / \text { year }\right)\end{array}$ & $\begin{array}{l}\text { Projected } \\
\text { Operating } \\
\text { Cost } \\
\left(\$ / \mathrm{ft}^{2} / \text { year }\right)\end{array}$ & $\begin{array}{l}\text { Estimated } \\
\text { Savings } \\
\text { (\$/ft } / \mathrm{ft}^{2} / \text { year) }\end{array}$ \\
\hline Energy & & $\$ 1.93$ & $\$ 1.85$ & $\$ 0.08$ \\
\hline Operations & & $\$ 3.70$ & $\$ 3.26$ & $\$ 0.44$ \\
\hline High performance building core & $\$ 0.35$ & & & $\$ 0.07$ \\
\hline Systems integration & $\$ 0.22$ & & & $\$ 0.22$ \\
\hline Enterprise operations & $\$ 0.29$ & & & $\$ 0.22$ \\
\hline Total (per square foot) & $\$ 0.86$ & $\$ 5.63$ & $\$ 5.11$ & $\$ 0.52$ \\
\hline Simple Payback & & & & 1.7 years \\
\hline
\end{tabular}

Note that Table 3-1 shows the calculated investment, savings and simple payback for the GSA-owned inventory in scope. We used GSA's 2008 energy costs of $\$ 1.93$ per square foot, and GSA's estimates for operations costs.

\subsection{Return on Investment}

We developed a hierarchical smart building model to calculate the return on investment for the smart building strategies. Table 3-2 shows the estimated investment, savings, and simple payback for the GSA-owned inventory. The analysis does not include leased buildings with Government Option to Purchase or large longterm leases.

We present the financial results three ways:

- Energy benefits only (improved energy efficiency)

- Operations benefits only (enhanced operational effectiveness)

- Energy and operations benefits combined

It is important to note that the return estimates do not include any energy savings associated with the high performance building control core included and funded as part of the efforts under the American Recovery and Reinvestment Act. In other words, the energy savings estimated is only the result of systems integration and enterprise management within the scope of Smart Buildings. 
Table 3-2: Estimated Investment, Savings, and Simple Payback

\begin{tabular}{|c|c|c|c|}
\hline $\begin{array}{c}\text { Quantity } \\
\text { Scope of Benefits }\end{array}$ & Investment & Savings & Simple Payback \\
\hline \multicolumn{4}{|l|}{ Energy benefits only } \\
\hline \$ per square foot & $\$ 0.86$ & $\$ 0.08$ & \multirow[t]{2}{*}{11.2 years } \\
\hline Total portfolio in scope & $\$ 130$ million & $\$ 12$ million & \\
\hline \multicolumn{4}{|l|}{ Operations benefits only } \\
\hline$\$$ per square foot & $\$ 0.86$ & $\$ 0.44$ & \multirow[t]{2}{*}{1.9 years } \\
\hline Total portfolio in scope & $\$ 130$ million & $\$ 67$ million & \\
\hline \multicolumn{4}{|c|}{ Energy and Operations benefits } \\
\hline$\$$ per square foot & $\$ 0.86$ & $\$ 0.52$ & \multirow[t]{2}{*}{1.7 years } \\
\hline Total portfolio in scope & $\$ 130$ million & \$78 million & \\
\hline
\end{tabular}

Note: Appendices C and D provide more detail on the methods, assumptions, and rationale for the financial analysis. Appendix $D$ provides a detailed analysis summary and pro-forma.

Tables 3-1 and 3-2 show that Smart Building Improvements can:

- Reduce energy costs by $4 \%$, from $\$ 1.93 / \mathrm{ft}^{2}-\mathrm{yr}$ to $\$ 1.85 / \mathrm{ft}^{2}-\mathrm{yr}$

- Note that if the energy savings attributed to the High Performance Building Control Core is included, energy costs are reduced by $14 \%$, from $\$ 1.93 / \mathrm{ft}^{2}-\mathrm{yr}$ to $\$ 1.66 / \mathrm{ft}^{2}-\mathrm{yr}$.

- Reduce operating costs by an estimated $12 \%$, from roughly $\$ 3.70 / \mathrm{ft}^{2}-\mathrm{yr}$ to $\$ 3.26 / \mathrm{ft}^{2}-\mathrm{yr}$

To achieve this will require:

- An incremental investment in the core building systems of $\$ 0.35 / \mathrm{ft}^{2}$

- An investment in systems integration of $\$ 0.22 / \mathrm{ft}^{2}$

- An investment in enterprise operations of $\$ 0.29 / \mathrm{ft}^{2}$ 


\section{GSA}

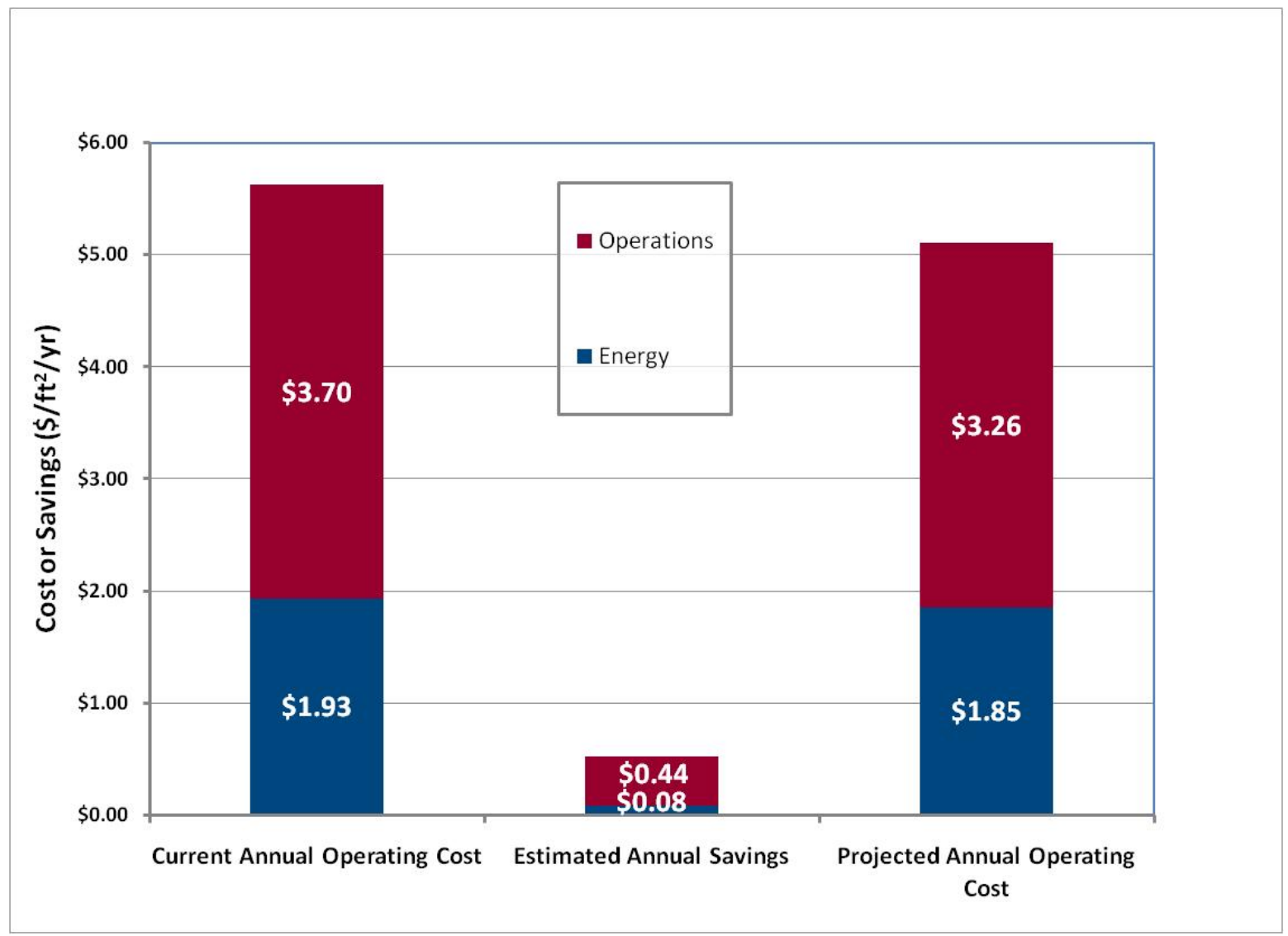

Figure 3-1: Estimated Savings and Cost for Energy and Operations Benefits 


\subsection{Estimated Savings}

For this analysis, we will refer to the three savings categories as follows:

- Improved energy efficiency as Energy

- Enhanced operational effectiveness as Operations

- Combined energy and operations savings as Total

Table 3-4 summarizes the savings estimates by strategies and by categories.

Table 3-4: Summary of Estimated Savings

\begin{tabular}{|c|c|c|c|}
\hline \multirow[t]{2}{*}{ Strategy } & \multicolumn{3}{|c|}{$\begin{array}{c}\text { Estimated Annual Savings } \\
\left(\$ / \mathrm{ft}^{2} / \text { year }\right)\end{array}$} \\
\hline & Energy & Operations & $\begin{array}{c}\text { Total } \\
\text { Energy \& Operations }\end{array}$ \\
\hline High performance building core & $\$ 0.00$ & $\$ 0.07$ & $\$ 0.07$ \\
\hline Systems integration & $\$ 0.04$ & $\$ 0.19$ & $\$ 0.22$ \\
\hline Enterprise operations & $\$ 0.04$ & $\$ 0.19$ & $\$ 0.22$ \\
\hline Total (per square foot) & $\$ 0.08$ & $\$ 0.44$ & $\$ 0.52$ \\
\hline GSA Portfolio & \multicolumn{3}{|c|}{ Total Savings } \\
\hline Total Savings & \$12 million & $\$ 67$ million & \$78 million \\
\hline
\end{tabular}

Key observations on estimated savings in Table 3-4:

- Energy savings are small relative to operational savings. The GSA portfolio is already at levels of energy efficiency that are better than most commercial buildings. While the potential improvement in energy costs appears small on a per square floor space basis, it is still substantial.

- Conversely, operational savings are large relative to energy savings, representing the potential contribution of systems, processes, and training deployed under the Smart Buildings program.

- Potential savings yielded by productivity enhancement are potentially very large relative to both energy and operations. This is of course due to the cost of labor per square foot, such that even a small improvement amounts to substantial savings. However, these benefits do not accrue directly to the GSA and are not quantified or included in the financial analysis.

Additional details on the estimated savings, including the assumptions and rationale, are in Appendix C, and a detailed pro forma is presented in Appendix D. In the pro forma, the savings figures shown denote annual savings. The savings are based on the nominal target scope of 150 million square feet, and, in effect, the pro-forma starts after construction finishes. In the case of a five-year action plan (Part 4), that would be in 2014. 


\subsection{Estimated Costs and Investment}

Estimated costs include operating costs for energy and operations(Table 3-5), as well as the costs of implementation for the Smart Building strategies (Table 3-6).

Table 3-5: Operating Costs for Energy, Operations, and Labor

\begin{tabular}{|l|rr|}
\hline \multicolumn{1}{|c|}{ Category } & \multicolumn{2}{|c|}{$\begin{array}{c}\text { Estimated Annual Operating Cost } \\
\left(\$ / \mathrm{ft}^{2} / \text { year) }\right.\end{array}$} \\
\hline Energy & & $\$ 1.93$ \\
\hline Operations & $\$ 3.70$ \\
\hline Total (per square foot) & $\$ 5.63$ \\
\hline
\end{tabular}

Table 3-6: Summary of Estimated Investment

\begin{tabular}{|l|rr|}
\hline \multicolumn{1}{|c|}{ Strategy } & \multicolumn{3}{|c|}{$\begin{array}{c}\text { Estimated Investment } \\
\left(\mathbf{\$} / \mathbf{f t}^{\mathbf{2}} \mathbf{)}\right.\end{array}$} \\
\hline & & $\$ 0.35$ \\
\hline High performance building core & & $\$ 0.22$ \\
\hline Systems integration & & $\$ 0.29$ \\
\hline Enterprise operations & & $\$ 0.86$ \\
\hline Total (per square foot) & & \\
\hline \multicolumn{1}{|c|}{ GSA Portfolio } & Total Cost & $\mathbf{\$ 1 3 0 \text { million }}$ \\
\hline Total & & \\
\hline
\end{tabular}

Key notes and observations on estimated costs are as follows:

- The incremental cost of the high performance building control core is the largest implementation cost, and the cost decreases with upward progression in the Smart Building Model (Figure 1-1).

- The high performance building control core consists of the following elements:

- HVAC controls optimization

- Lighting controls optimization and integration

- Advanced metering

- Network-enabled security

- Commissioning and recommissioning

- Vertical network infrastructure

The incremental cost of the high performance building control core consists only of the network infrastructure to support building systems, as this is what is required for Smart Buildings in addition to that covered by efforts in accordance with the American Reinvestment and Recovery Act. It is assumed that the larger infrastructure renewal efforts include all elements of the High Performance Building Control core other than the network infrastructure. The vertical network 
infrastructure may be expandable to a converged network capable of offering voice, video, and data services to tenants. The cost associated with such expansion is estimated to add $\$ 0.30$ to $\$ 0.65$ per square foot to the cost of the fundamental vertical network infrastructure. However, only the cost of the base vertical network infrastructure is included in the financials.

Additional details on the cost estimates, including the rationale, are found in Appendix C, and a detailed pro forma is presented in Appendix D. In the pro forma, the total investment is shown in Year 0 . In effect, the pro-forma starts after construction finishes, and in the case of a five-year action plan (Part 4), that would be in 2014.

\subsection{Scalability}

As stated previously, the financial analysis presented is based on a scope that covers 150 million square feet and 300 buildings. However, over time the actual scope in implementation may of course vary from plan, and it is important to understand how the financials scale with the scope of the Smart Buildings deployment. To this end, a scalability analysis presents simple payback as a function of the gross floor space in scope, as shown in the chart below.

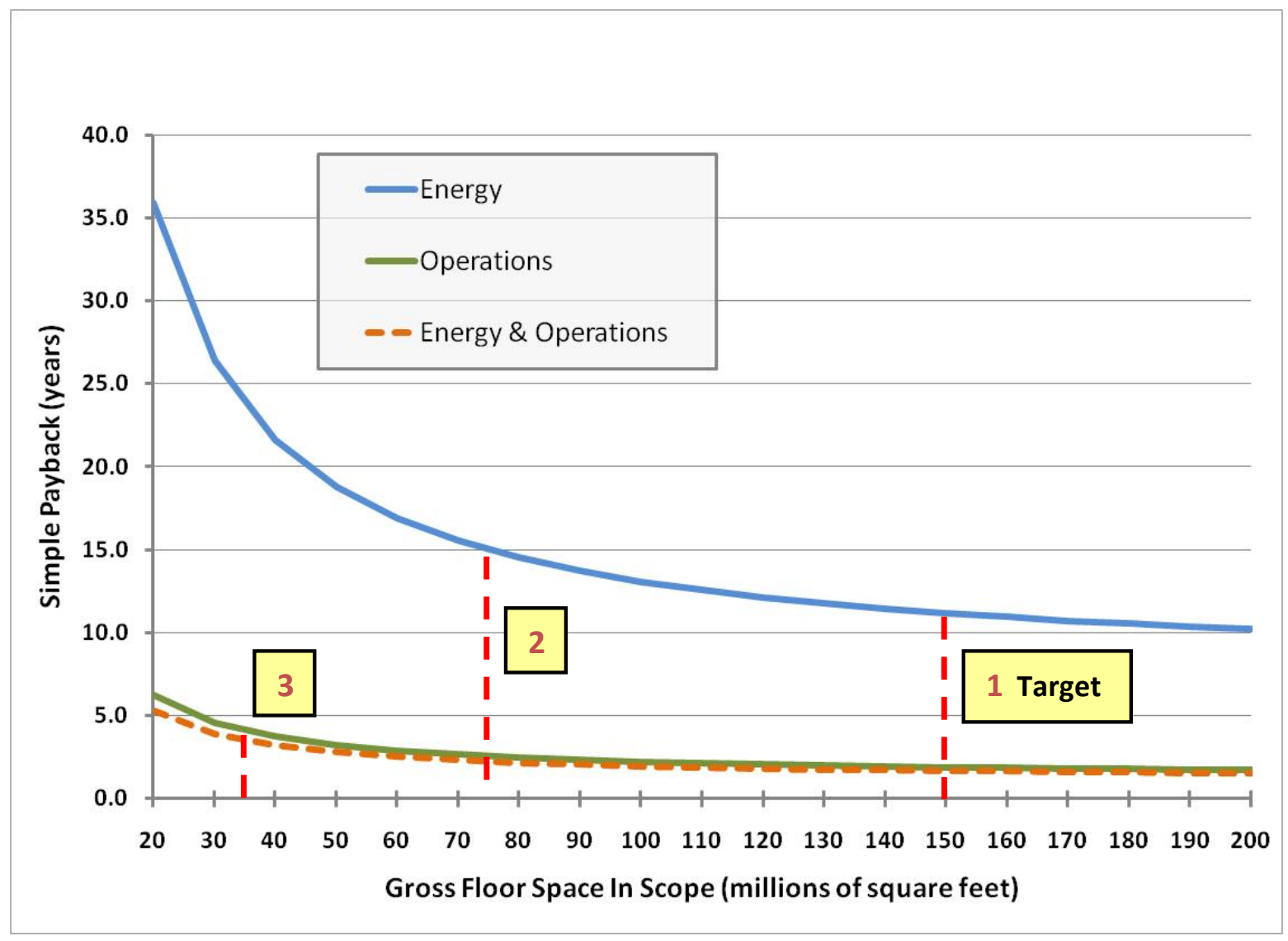

Figure 3-2: Scalability of Smart Buildings 
From this illustration of scalability, the following points and conclusions apply (per the corresponding numbered labels):

1. The nominal target scope of the analysis is 300 buildings comprised of $\mathbf{1 5 0}$ million square feet of gross floor space.

2. Simple payback, and the financials in general, are not very sensitive to gross floor space in scope above 75 million square feet. However, reducing the scope below 75 million square feet yields diminishing financial returns if only energy savings are considered. This is primarily due to the fact that the uppermost layer of the Smart Buildings pyramid, Enterprise Management capability, requires a relatively large and fixed investment that is not very sensitive to project scope or scale. Investments associated with the High Performance Building Control Core and Systems Integration, on the other hand, scale in direct relation to the gross floor space in scope.

3. When both energy and operations benefits are considered, Smart Buildings' financial scalability extends all the way down to 20 million square feet, with diminishing returns taking hold at about 35 million square feet.

Overall, Smart Buildings appear to be fairly scalable except perhaps on a very small scale where the investment in the enterprise management component is too large relative to the benefits. However, the high performance building control core, and systems integration layers appear to scale well across the entire range of gross floor space.

\section{Part 4. Recommended Action Plan}

We developed a five-year action plan that recommends steps to achieve the goals of a Smart Building initiative. The five-year action plan is intended to work in concert with public building renewal under the American Recovery and Reinvestment Act, and is based on the scope and depth discussed in prior sections of 150 million square feet and 300 buildings.

The overall strategy for the Action Plan has three steps:

\section{Planning}

2. Pilots

3. Broad deployment

A key element of the strategy is that the lessons learned from the pilot projects be incorporated into the Broad Deployment step. Given the accelerated nature of the process, Broad Deployment will start prior to the completion of the Pilots, and there will need to be real-time evaluation built into the process to ensure that the deployment projects learn from the Pilots.

This action plan can be applied to a smaller or larger scope of buildings and gross floor space, and it may also be accelerated or decelerated with respect to time. It is 
the intent of this report to provide a starting point and alternatives from which more detailed and specific plans may be developed. The action plan is detailed in Table 41 , and illustrated by Figure 4-1 below.

Table 4-1: Action Plan

\begin{tabular}{|c|c|c|}
\hline \multicolumn{2}{|c|}{ Year } & Activity \\
\hline 1 & 2009 & $\begin{array}{l}\text { - Incorporate integration language and network requirements into the revised } \\
\text { P100 and Smart Building Design Guide } \\
\text { - } \quad \text { Issue revised P100 and Smart Building Design Guide } \\
\text { High Performance Controls Core upgrades on approximately } 300 \text { buildings } \\
\text { begins under ARRA funding with work continuing through } 2012 \\
\text { - Include Smart Buildings work in selected ARRA projects as pilots, and based } \\
\text { on experience, adjust and expand to all GSA projects over the next } 18 \\
\text { months. } \\
\text { Conduct Building Operations Centers Research project } \\
\circ \quad \text { Review existing sites (GemNet, Boston Properties, Cisco, State of } \\
\quad \text { Missouri, University of NC, etc.) } \\
\circ \quad \text { Review national energy aggregation program (EU-AS) } \\
\circ \quad \text { Compile best practices and processes } \\
\quad \text { Identify key software elements, protocols and standards, potential } \\
\quad \text { suppliers } \\
\text { - Develop a plan to test and deploy broadly within GSA } \\
\text { - Identify regions and sites to participate in pilots } \\
\text { Issue RFP for pilot software and systems } \\
\text { Begin pilot projects }\end{array}$ \\
\hline 2 & 2010 & $\begin{array}{ll} & \text { Evaluate pilot results } \\
\text { - } & \text { Develop new processes as required } \\
\text { - } & \text { Roll out nationally } \\
\text { - } & \text { Regional pilot sites come online } \\
\text { - } & \text { Evaluate pilot site results } \\
\text { - } & \text { Eving pilot results develop a national rollout plan } \\
\text { software and systems requirements } \\
\quad \circ \quad \text { Issue an RFP for production software and systems, and evaluate RFP } \\
\quad \text { results } \\
\quad \text { Issue contracts for deployment } \\
\text { - Development of measurement and verification plans and processes. }\end{array}$ \\
\hline 3 & 2011 & $\begin{array}{l}\text { - } \quad \text { Staff development and training } \\
\text { - } \quad \text { Continued evaluation, adjustment, and subsequent deployment of piloted } \\
\text { concepts, technologies, and processes. } \\
\text { - } \quad \text { Retrospective evaluation of projects completed with lessons learned to be } \\
\text { incorporated in current and future projects. } \\
\text { - } \quad \text { Measurement and verification of projects completed. } \\
\text { - Begin broad national deployment }\end{array}$ \\
\hline $4-5$ & $\begin{array}{c}2012 \\
\text { to } \\
2013\end{array}$ & $\begin{array}{ll} & \text { Continued measurement and verification. } \\
\text { - } & \text { Continued retrospective evaluation and adjustment. } \\
\text { - } & \text { Broad deployment of all programs. }\end{array}$ \\
\hline
\end{tabular}


GSA

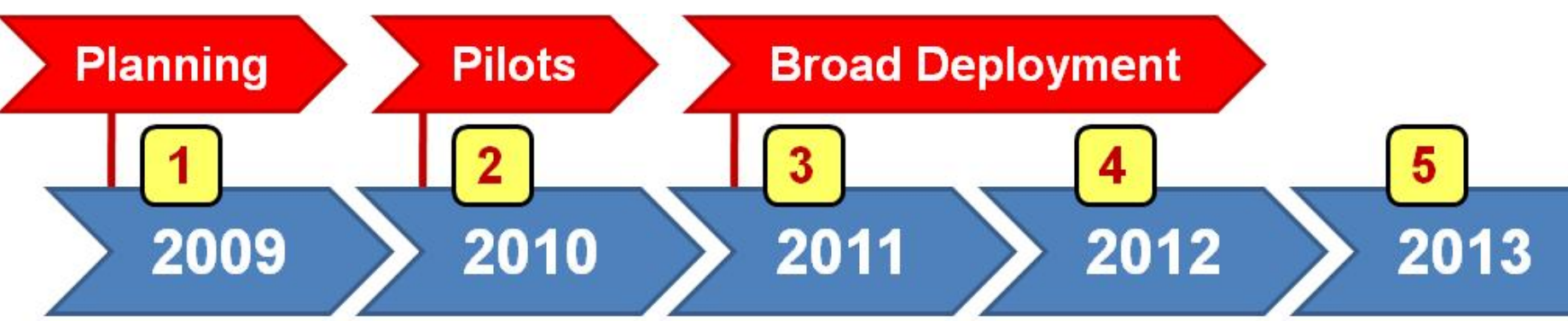

\begin{tabular}{|c|c|c|c|c|c|}
\hline 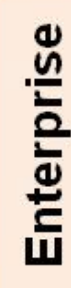 & $\begin{array}{l}\text { - Ops. centers } \\
\text { research } \\
\text { - Identification of } \\
\text { pilot regions and } \\
\text { sites } \\
\text { - Develop pilot } \\
\text { systems }\end{array}$ & $\begin{array}{l}\text { - Evaluate pilots } \\
\text { - Develop } \\
\text { processes } \\
\text { - Plan for broad } \\
\text { deployment } \\
\text { - Refine and fully } \\
\text { develop systems }\end{array}$ & $\begin{array}{l}\text { - Develop and } \\
\text { train staff } \\
\text { - Deploy systems } \\
\text { - Test operations } \\
\text { centers }\end{array}$ & $\begin{array}{l}\text { - Broad deployment } \\
\text { underway }\end{array}$ & $\begin{array}{l}\text { Broad } \\
\text { deployment } \\
\text { underway }\end{array}$ \\
\hline $\begin{array}{l}\frac{5}{0} \\
\frac{0}{0} \\
\frac{10}{0} \\
\end{array}$ & $\begin{array}{l}\text { - Incorporate into } \\
\text { P100 and design } \\
\text { guide } \\
\text { - Include this } \\
\text { scope in selected } \\
\text { pilot building } \\
\text { projects }\end{array}$ & $\begin{array}{l}\text { - Evaluate pilots } \\
\text { - Develop } \\
\text { standard } \\
\text { processes } \\
\text { - Plan for broad } \\
\text { deployment } \\
\text { - Conduct training }\end{array}$ & $\begin{array}{l}\text { Broad } \\
\text { deployment } \\
\text { underway }\end{array}$ & $\begin{array}{l}\text { - Broad deployment } \\
\text { underway }\end{array}$ & $\begin{array}{l}\text { Broad } \\
\text { deployment } \\
\text { underway }\end{array}$ \\
\hline $\begin{array}{l}0 \\
0 \\
0 \\
0 \\
0 \\
0\end{array}$ & $\begin{array}{l}\text { - Revised P100 } \\
\text { and design guide } \\
\text { - Included in } \\
\text { design for } \\
\text { upgrades and } \\
\text { retrofits under } \\
\text { ARRA }\end{array}$ & $\begin{array}{l}\text { - Apply in building } \\
\text { projects under } \\
\text { ARRA } \\
\text { - Broad } \\
\text { deployment } \\
\text { underway }\end{array}$ & $\begin{array}{l}\text { Broad } \\
\text { deployment } \\
\text { underway }\end{array}$ & $\begin{array}{l}\text { - Broad deployment } \\
\text { underway }\end{array}$ & $\begin{array}{l}\text { Broad } \\
\text { deployment } \\
\text { underway }\end{array}$ \\
\hline
\end{tabular}

Figure 4-1: Recommended Action Plan

GSA Smart Buildings Report

Page 35

April 8, 2009 


\subsection{Scenario Analyses for Action Plan Deployment}

As part of the development process for the Recommended Action Plan, we developed and analyzed multiple scenarios for the initial deployment of the demonstration projects. These scenarios look at different numbers, types, locations and size of the pilots, present arguments for and against each alternative, and result in initial recommendations. One of these scenarios "Location of Pilot Projects" is illustrated in Figure 4-2 below and the full set of scenarios is included in Appendix E.

The purpose of the Scenario Analyses is to have a process for weighing and evaluating the different factors that will impact the analysis. We expect that additional factors and weights will be applied to this analysis when additional information on the Recovery Actand other sources becomes available. 


\section{B. Location of Pilot Projects}

Background

The issues related to Location of pilot projects are as follows:

1. Expertise and experience with smart building retrofits is not equally distributed across all Regions

2. Regions with experience may be able to quickly conduct pilots

3. Regions without experience may require additional resources

4. Multiple pilots in the same region allow for the demonstration of a Regional Operating Center

\section{Scenarios for Location of Pilot Projects:}

\section{B-1. Pilots all located in One Region}

Pro:

- Least expensive option.

- Could pick region with most experience and expertise for rapid demonstration

- Could demonstrate a Regional Operating Center

Con:

- Not equitable for other regions

- Wouldn't learn how start up costs would impact all regions

\section{B-2. Pilots located in Three Regions}

Pro:

- Less expensive option.

- Some additional information would be learned about smart building deployment in different Regions

- Could demonstrate a Regional Operating Center if multiple pilots included in any one Region.

Con:

- Information from three Region may not generalize to the rest of GSA's portfolio

\section{B-3. Pilots located in All Regions}

Pro:

- Would provide experience for all Regions

- Could demonstrate a Regional Operating Center if multiple pilots included in any one Region.

Con:

- Most expensive option.

- Regions without prior experience may require additional resources

\section{Recommendation:}

B-3. Pilots in All Regions

Additional recommendation:

- Establish a peer-to-peer team with representatives from each Region for Regions to learn from each other's experience.

Figure 4-2: Example of Action Plan Scenario Analysis. 


\section{Revision History of the Report}

The first version, or Phase 1, of the Smart Buildings Business Case and Action Plan was completed in early February 2009. In the transformation from the Phase 1 report to this Phase 2 report, the primary changes are as follows:

1. The emergence of a defined scope of work for public building renewal in accordance with the American Recovery and Reinvestment Act, and the understanding that this work will absorb a portion of the Smart Buildings implementation and cost, most notably the majority of the High Performance Building Control Core.

2. The decision to focus the financial analysis on energy and operations benefits and savings, and to set aside productivity benefits.

3. Refactoring of the financials based on the defined scope and assumptions.

4. Recomposition of the Action Plan, with alternative scopes for pilots and deployment.

Table 4-2 below lists the major changes in more detail and, where applicable, how they impacted the outcomes.

Table RH-1: Phase 1 to Phase 2 Changes

\begin{tabular}{|c|c|c|c|}
\hline \multicolumn{2}{|r|}{ Part or Appendix } & What changed? & How did it change? \\
\hline \multicolumn{2}{|c|}{ Executive Summary } & $\begin{array}{l}\text { See the changes for the } \\
\text { individual sections below. }\end{array}$ & \\
\hline 1 & Background & $\begin{array}{l}\text { Added vertical network } \\
\text { infrastructure to High } \\
\text { Performance Building Core to } \\
\text { support building systems } \\
\text { Added expanded network } \\
\text { infrastructure to Systems } \\
\text { Integration to support } \\
\text { Converged Networks option. } \\
\text { Added the characterization and } \\
\text { discussion of scope, with scale } \\
\text { and depth of efforts, what is } \\
\text { covered under ARRA, and what } \\
\text { is covered under Smart } \\
\text { Buildings. } \\
\text { Added training and certification } \\
\text { program considerations to the } \\
\text { Smart Building challenges } \\
\text { regarding contractors, } \\
\text { integrators, and operators (per } \\
\text { comments from Teng). } \\
\text { Added scope and scale of public } \\
\text { building renewal and Smart } \\
\text { Buildings as a GSA-specific } \\
\text { challenge. }\end{array}$ & \\
\hline
\end{tabular}




\begin{tabular}{|c|c|c|c|}
\hline & Part or Appendix & What changed? & How did it change? \\
\hline 2 & Priority Actions & $\begin{array}{l}\text { Under Recommendation \#1, } \\
\text { added remarks about the High } \\
\text { Performance Building Core } \\
\text { inclusion in public building } \\
\text { renewal under ARRA. } \\
\text { Under Recomendation\#2, added } \\
\text { consideration of demand } \\
\text { response. }\end{array}$ & \\
\hline 3 & $\begin{array}{l}\text { Cost, Investment, and } \\
\text { Savings }\end{array}$ & $\begin{array}{l}\text { Updated the financial analysis } \\
\text { methodology to include scope } \\
\text { definition. } \\
\text { Indicated conservative nature of } \\
\text { financial analysis. } \\
\text { Added section } 3.2 \text { Input and } \\
\text { Assumptions with sources of } \\
\text { operating costs and scope } \\
\text { assumptions. } \\
\text { Updated section } 3.3 \text { Investment } \\
\text { and Return. } \\
\text { Applied a limited scope of } \\
\text { energy benefits and savings } \\
\text { associated with the High } \\
\text { Performance Building Core, since } \\
\text { the bulk of energy savings are } \\
\text { due to efforts funded by ARRA. } \\
\text { Reduced the cost of the High } \\
\text { Performance Building Core to } \\
\text { reflect the cost of the network } \\
\text { infrastructure element only, per } \\
\text { the assumption that the other } \\
\text { elements are covered by efforts } \\
\text { funded by ARRA. } \\
\text { Removed productivity benefits } \\
\text { from the financial analysis. } \\
\text { Changed the analysis to depict } \\
\text { updated with revised financials. } \\
\text { energy and operations benefits } \\
\text { independently, and energy and } \\
\text { operations benefits combined. } \\
\text { Noted that productivity benefits } \\
\text { potentially amount to large } \\
\text { Ading, but removed } \\
\text { fution. }\end{array}$ & $\begin{array}{l}\text { Quantified energy savings due to } \\
\text { Smart Buildings decreased from } \\
14 \% \text { to } 4 \% \text {, or from } \$ 0.27 \text { to } \\
\$ 0.08 \text {; however, the identified } \\
\text { energy savings remains at an } \\
\text { average of } 14 \% \text {. } \\
\text { The investment for the high } \\
\text { performance building control } \\
\text { core decreased from } \$ 2.74 \text { to } \\
\$ 0.35 \text { per square foot with the } \\
\text { understanding that most of the } \\
\text { core elements are covered by } \\
\text { efforts under ARRA. } \\
\text { The investment for systems } \\
\text { integration decreased from } \\
\$ 0.56 \text { to } \$ 0.22 \text { per square foot. } \\
\text { Enterprise management cost } \\
\text { increased from } \$ 0.17 \text { to } \$ 0.29 \\
\text { per square foot to reflect } \\
\text { practical experience as well as } \\
\text { risk associated with these items. } \\
\text { With the revised scope the } \\
\text { overall investment dropped from } \\
\text { more than } \$ 600 M \text { to } \$ 130 M . \\
\text { With the revised scope and } \\
\text { change in investment, the } \\
\text { simple payback for both energy } \\
\text { and operations savings } \\
\text { decreased from approximately } 4 \\
\text { years to } 1.7 \text { years. }\end{array}$ \\
\hline 4 & Action Plan & $\begin{array}{l}\text { Updated the action plan per the } \\
\text { revised scope to be consistent } \\
\text { with efforts under ARRA. } \\
\text { Added pilot and deployment } \\
\text { alternatives to the action plan in } \\
\text { a new Appendix. } \\
\text { Added the action plan } \\
\text { illustration. }\end{array}$ & \\
\hline
\end{tabular}




\begin{tabular}{|c|c|c|c|}
\hline \multicolumn{2}{|r|}{ Part or Appendix } & What changed? & How did it change? \\
\hline $\mathbf{A}$ & Needs Analysis & Unchanged. & \\
\hline B & $\begin{array}{l}\text { Details on Technical } \\
\text { Strategies for Smart } \\
\text { Buildings }\end{array}$ & $\begin{array}{l}\text { Added Item } 8 \text { under High } \\
\text { Performance Building Control } \\
\text { Core, Network Infrastructure } \\
\text { and Converged Networks. } \\
\text { Under Enterprise Management, } \\
\text { added building performance } \\
\text { labeling and support for disaster } \\
\text { management (per input from } \\
\text { Teng). }\end{array}$ & \\
\hline $\mathbf{C}$ & $\begin{array}{l}\text { Financial Analysis } \\
\text { Assumptions }\end{array}$ & $\begin{array}{l}\text { Updated all financial inputs and } \\
\text { assumptions per revised scope. } \\
\text { Again, applied a limited scope of } \\
\text { energy benefits and savings } \\
\text { associated with the High } \\
\text { Performance Building Core, since } \\
\text { the bulk of energy savings are } \\
\text { due to efforts funded by ARRA. } \\
\text { Changed the investment for } \\
\text { systems integration to reflect } \\
\text { per building and per unit floor } \\
\text { space costs. } \\
\text { Changed the investment for } \\
\text { enterprise management to } \\
\text { reflect practical experience as } \\
\text { well as risk associated with this } \\
\text { item. }\end{array}$ & $\begin{array}{l}\text { Quantified energy savings due to } \\
\text { Smart Buildings decreased from } \\
14 \% \text { to } 4 \% \text {, or from } \$ 0.27 \text { to } \\
\$ 0.08 ; \text { however, the identified } \\
\text { energy savings remains at an } \\
\text { average of } 14 \% \text {. } \\
\text { The investment for systems } \\
\text { integration decreased from } \\
\$ 0.56 \text { to } \$ 0.22 \text { per square foot. } \\
\text { Enterprise management cost } \\
\text { increased from } \$ 0.17 \text { to } \$ 0.29 \\
\text { per square foot to reflect } \\
\text { practical experience as well as } \\
\text { risk associated with these items. } \\
\text { With the revised scope, overall } \\
\text { investment dropped from more } \\
\text { than } \$ 600 M \text { to } \$ 130 M \text {. }\end{array}$ \\
\hline $\mathbf{D}$ & $\begin{array}{l}\text { Detailed Financial Analysis } \\
\text { Summary and Pro-forma }\end{array}$ & $\begin{array}{l}\text { Two pro forma worksheets } \\
\text { present the two scopes of } \\
\text { benefits: Energy only, and } \\
\text { energy and operations. } \\
\text { Productivity is no longer } \\
\text { included in the pro forma. }\end{array}$ & \\
\hline $\mathbf{E}$ & Action Plan Scenarios & $\begin{array}{l}\text { Added action plan scenarios that } \\
\text { examine variables with } \\
\text { advantages, disadvantages, and } \\
\text { recommendations. }\end{array}$ & \\
\hline $\mathbf{F}$ & $\begin{array}{l}\text { Network Infrastructure for } \\
\text { Building Systems }\end{array}$ & $\begin{array}{l}\text { Added a diagram to conceptually } \\
\text { illustrate the vertical network } \\
\text { infrastructure for building } \\
\text { system support. }\end{array}$ & \\
\hline $\mathbf{G}$ & $\begin{array}{l}\text { Information Technology } \\
\text { Inputs to the Smart Building } \\
\text { Business Case }\end{array}$ & $\begin{array}{l}\text { Replaced original FAS/Noblis } \\
\text { content with this new content } \\
\text { from FAS. }\end{array}$ & \\
\hline
\end{tabular}


Table 4-3 summarizes the changes in the financials from Phase 1 to Phase 2 based on the scope of benefits and savings that includes energy and operations.

Table RH-2: Summary of Financial Changes from Phase 1 to Phase 2

\begin{tabular}{|c|c|r|l|r|}
\hline Quantity & Units & Phase 1 & Change & Phase 2 \\
\hline $\begin{array}{c}\text { Operating Costs } \\
\text { Energy }\end{array}$ & $\$ / \mathrm{ft}^{2}$ & $\$ 1.93$ & Unchanged & $\$ 1.93$ \\
\hline Operations & $\$ / \mathrm{ft}^{2}$ & $\$ 3.70$ & Unchanged & $\$ 3.70$ \\
\hline Total & $\$ / \mathrm{ft}^{2}$ & $\$ 5.63$ & Unchanged & $\$ 5.63$ \\
\hline $\begin{array}{c}\text { Investment } \\
\text { High Performance } \\
\text { Building Control Core }\end{array}$ & & & & $\$ \mathrm{ft}^{2}$ \\
Systems Integration & $\$ / \mathrm{ft}^{2}$ & $\$ 2.74$ & $\begin{array}{l}\text { Decreased per } \\
\text { coverage by ARRA. }\end{array}$ & $\$ 0.35$ \\
\hline Enterprise Management & $\$ / \mathrm{ft}^{2}$ & $\$ 0.56$ & Re-estimated. & $\$ 0.22$ \\
\hline Total & $\$ / \mathrm{ft}^{2}$ & $\$ 0.17$ & Re-estimated. & $\$ 0.86$ \\
\hline [Million USD] & $\$$ & $\$ 3.47$ & & $\$ 130$ \\
\hline Savings & $\$ 611$ & & $\$ 0.08$ \\
\hline Energy & $\$ / \mathrm{ft}^{2}$ & $\$ 0.27$ & $\begin{array}{l}\text { Reduced scope of } \\
\text { energy benefits. }\end{array}$ & $\$ 0.44$ \\
\hline Operations & $\$ / \mathrm{ft}^{2}$ & $\$ 0.60$ & $\begin{array}{l}\text { Minor reduction in } \\
\text { operations benefits. }\end{array}$ \\
\hline Total & $\$ / \mathrm{ft}^{2}$ & $\$ 0.87$ & & $\$ 0.52$ \\
\hline [Million USD] & $\$$ & $\$ 153$ & & $\$ 78$ \\
\hline Payback & $y e a r s$ & 4.0 & & 1.1 \\
\hline
\end{tabular}




\section{Appendix A: Needs Analysis Summary}

A series of interviews were conducted with GSA staff as part of this project. The results of these interviews where summarized in a report issued in December 2008 titled "GSA Energy Smart Buildings Needs Analysis". The following is a summary of findings from the interviews.

\section{Stakeholder Interviews}

Interviews with key internal stakeholders covered:

- GSA's level of familiarity with Smart Building concepts

- Prior experience with smart building technologies

- Perceived advantages, disadvantages, and potential issues

- Specific constraints, limitations or special needs

- Appropriate implementation strategies

Participants for the interviews were recommended by the GSA project team based on their ability to provide input into different aspects of the organization. In-person group and individual and group phone interviews were conducted by the LBNL consulting team with 47 GSA representatives including:

- 24 representatives from GSA regions representing property management, sustainability, administration, program management, Building Information Modeling (BIM) and information technology;

- 23 representatives from GSA Central Office representing security, information technology, energy management, sustainability, vendor alliance, engineering, real estate, operations and maintenance, courthouse programs and integrated technology solutions.

\section{Interview Findings}

Highlights of interviews and findings related to the concept of smart buildings, the four goals, and implementation challenges and impediments.

\section{Smart Building Attributes Well Understood}

Individual interviews and focus groups solicited feedback on a definition of Smart Buildings included in the materials distributed in advance. Almost all participants (45 out 47) expressed familiarity with the concept and the benefits resulting from running buildings in a world of telecom/data/controls convergence.

Aggregating comments, a consensus GSA definition of Smart Buildings includes:

- Systems to monitor and manage efficiently-HVAC, lighting, water, energy usage, fire and life safety systems.

- Integrated systems for efficient operations including remote monitoring and management. 
- Coordinated security systems that can respond to routine and unexpected situations.

- Buildings that can adjust to external and internal changes including occupancy.

- Building information models that improve efficiency and lower life cycle costs.

\section{Goal 1: Achieve Energy Efficiency Mandates}

The vast majority of those interviewed identified the urgent need to achieve a high level of energy efficiency and sustainability as the key driver for implementing Smart Buildings. GSA has already established a leadership role in this area, achieving significantly higher energy efficiency then the private sector. However, existing internal mandates coupled with legislation requires continuous improvement in efficiency. The ability to better manage the information from building systems and to optimize the building systems is seen as a key element in achieving these goals.

- Mandates for energy management and sustainability.

- GSA has a long track record in energy efficiency and has made significant progress.

- Low hanging fruit are gone and business as usual will not meet the mandates.

- Reductions in energy usage by tenants will be required to meet mandates; GSA needs information, systems and incentives to motivate individual tenants or agencies.

- Continuous-commissioning or retro-commissioning are key to improving and maintaining efficiency of existing buildings.

\section{Goal 2: Enhance Property Management}

Presently PBS owns or leases over 300 million square feet of space. Managing this vast portfolio is a challenge, especially given the vast variety of spaces, large numbers of historic properties and special operating requirements of tenants. Operations in general have been done locally within regions, typically using outsourced contractors. While this has generally worked well, and tenant satisfaction is high, there also are challenges with consistency and management level information. Smart Buildings offer the potential to readily accumulate information about buildings at a national level allowing for improved oversight and optimization from an operations perspective.

- GSA does not have adequate information about existing buildings and systems and some existing systems have issues of data quality and data consistency.

- There are issues with O\&M contractor effectiveness, incentives to save energy, and knowledge transfer when contractors change. 
- Off hours access and building operations requests are not consistently tracked and charged to tenants.

\section{Goal 3: Implement Network as a Common Building Infrastructure}

GSA tenants depend on voice, video and data telecommunications as an essential commodity not unlike water and electrical power. Similarly, the service can be delivered over a common infrastructure that is installed and maintained as part of the building infrastructure. Thus, the concept of a building "Network" as a fourth utility and the implementation of a common integrated wiring infrastructure that would transport voice, video, data, and BAS traffic over a converged IP backbone.

- The Network includes vertical building wiring including wiring closets, switches, routers, gateways, cross-connects and associated equipment.

- Enables the rapid transition to Voice over IP (VoIP) and other broadband services.

- Provides an integrated network for Building Automation System (BAS) data.

GSA is uniquely positioned to implement a common building infrastructure with its two major business lines and areas of expertise: PBS (building expertise) and FAS (IT/telecommunications expertise).

\section{Goal 4: Enhance Safety and Security}

Providing a safe and secure environment is a key priority for GSA. These systems offer the potential to be an attribute of a Smart Building solution providing enhanced security and information on occupancy for enhanced control and optimization.

- HSPD-12 requires standard credentials for physical and network access and GSA is working on understanding how this impacts their systems and business processes. Note that further study is recommended to fully understand how HSPD-12 and Smart Buildings impact one another.

- Current systems are good for fire protection but ongoing security challenges with attacks and terror persist.

- Desire better information on who is in a building, where, and building utilization.

\section{Challenges and Impediments}

The interviews resulted in many concerns regarding the potential implementation of Smart Buildings as a program. These are important to understand so that the master plan can properly plan for an implementation where these can be overcome.

- Budget constraints and funding for new initiatives.

- Systems must be highly reliable, failsafe, and tested properly. 
- Changing work patterns that impact building usage and space requirements.

- Security concerns limit sharing information and facilities between agencies.

- Balancing enhanced security with privacy concerns and tenant efficiency.

- Fire and Life Safety integration faces strict and varied code requirements.

- O\&M contractors lack the skills to use sophisticated systems; availability of skilled resources in remote locations.

- O\&M contractor motivation to support energy efficiency vs. tenant satisfaction.

- Large base of older and historical buildings with many different and proprietary systems.

- Concern that many existing systems are not operating properly or efficiently. 


\section{Appendix B: Technical Strategies for Smart Buildings}

\section{Strategy 1. Develop a High Performance Building Control Core}

The high performance building control core provides the necessary systems and technology to support Smart Building operations and to begin realizing many of the benefits related to improved energy efficiency. This strategy consists of several tactical elements. While many of these are consistent with current P-100 standards for new projects this strategy does recommend taking this approach further, to gathering even more benefits for new projects, as well as applying this approach as a retrofit or upgrade for existing facilities.

The strategy starts with the core building control systems, examining each system for how it can be both optimized for improved efficiency and how it can be prepared for future integration (see System Integration strategy below). The systems to be addressed are in priority order as follows:

1. HVAC Controls: The HVAC control system (often called a Building Automation System or BAS) is the system that is responsible for an estimated $40 \%$ of the energy usage in most facilities. Therefore, this system is also the top candidate for integration and optimization.

a. Optimization: There are many opportunities to utilize HVAC controls to dramatically impact the energy usage of a facility. This starts with basic strategies that are already required by the P-100 such as setpoint reset controls. There are, however, a number of more advanced strategies that are not yet in broad use across the GSA owned portfolio that should also be applied for both new and existing building projects. These include:

i. Demand Controlled Ventilation: In order to maintain a healthy ventilation level, ASHRAE Standard 62 specifies a fixed ventilation level for removal of contaminants and an additional amount of ventilation to disperse the $\mathrm{CO}_{2}$ impact of the occupants. During normal operation the building is kept ventilated based on the anticipated design occupancy. The standard does, however, allow for an alternate control strategy which measures the actual occupancy (typically through the use of $\mathrm{CO}_{2}$ sensors) and adjusts ventilation to reflect actual occupancy. Most importantly this strategy results in a healthy indoor environment and can also provide significant energy savings. Energy savings will vary depending on the building location and occupancy and can be calculated using widely available tools. HVAC energy savings for office buildings range from $3-20 \%$, or higher.

ii. Static Pressure Reset: While use of variable flow systems for both water and air have resulted in significant performance improvements in HVAC systems, they can be further optimized. 
This is done by dynamically resetting the static pressure setpoint based on system demand. An algorithm that looks at valve position as well as pressure is used to calculate the minimum acceptable pressure for proper system operation. This strategy reduces fan and pump power requirements and is estimated to reduce HVAC energy usage by $2-4 \%$.

iii. Chiller Plant Optimization: The majority of the energy usage by the HVAC system occurs in the chiller plant. There are number of algorithms available to optimize the chiller plant. These include strategies to automate the sequencing of the chillers, always choosing the most efficient combination of machines, to balancing the energy flow between the chiller and cooling tower. Chiller plant optimization provides an automated method to maximize efficiency of the chiller plant. Tools such as Energy Plus can be used to estimate anticipated savings which depend upon the plant design, climate and current operating procedures.

b. Integration and Interface: HVAC control systems are available today that support one or more well accepted open protocols including BACnet and LonTalk. Consideration of these standards is required on all new projects per P-100 and some existing systems can be readily upgraded to support these standards. Other systems may require replacement or connection using gateways or other protocol converters. The Smart Building interface to the HVAC control system needs to allow both monitoring and control. This will not only allow operators with proper access to view and modify the system, but also enable the use of automated inter-system strategies for further energy savings.

2. Lighting Controls: Lighting is the second largest energy consumer in most buildings, accounting for approximately $28 \%$ of consumption. Like HVAC it also has a large impact on the comfort and productivity of the building occupants. Traditionally lighting controls systems have been fairly basic, often consisting of manual light switches or circuit breakers. With these systems, the control of lighting is left up to the custodial crew or to the occupants resulting in inefficiency. GSA has been a leader in implementing more sophisticated lighting control systems and the current P-100 standards require several strategies including daylight harvest and occupancy sensing. Expanding the use of these systems in existing buildings and developing further integration for new projects offers the potential for both enhanced occupant productivity and improved energy efficiency.

a. Optimization: There are many opportunities to optimize lighting controls. Several of the strategies listed below are already required in the P-100 for new projects (as noted) however they are not assumed to be widely used by existing buildings. Others are new strategies for consideration on all projects. These include:

i. Daylight Harvesting (Note: Currently in P-100): Areas of a building which have available daylight can often have the lighting levels decreased or even shut off when adequate natural light is available. This strategy requires both 
measurement of light levels and either dimming or turning off banks of lights. Properly applied this has the potential for significant savings in the range of $10-25 \%$ of lighting energy use.

ii. Occupancy Sensing (Note: Currently in P-100): Occupancy sensing can be used to both turn on and turn off lights when rooms are occupied. Several variations of this strategy exist, the most common brings the lights on when movement is sensed and then off after no movement is observed for a time interval. An alternative strategy requires the occupant to manually turn on the lights upon entering a space and a sensor to automatically turn them off after a time interval. Recent studies have found that this strategy is even more effective in saving energy. Savings range from $5-10 \%$ of lighting energy use.

iii. Occupancy Based Scheduling: In most buildings, the lights are brought on following a fixed schedule regardless of actual occupancy. This is done to accommodate occupants as well as for the convenience of custodial crews. More accurately, matching lighting schedules to actual occupancy has the potential for significant savings. Within the lighting control system, this can be done by utilizing more restrictive schedules and then allowing occupants to perform a local override. Overrides are often done from wall-mounted switches or through the use of a telephone override. In an integrated system (see Systems Integration below) this can be further automated by connecting the lighting to other systems including security and HVAC. Reducing lighting use for a typical building by an hour a day will result in a $6 \%$ reduction of lighting energy usage.

iv. Active Façade Control: This describes the ability to have either occupant or automated control of shading systems. Controlling solar fenestration provides the ability both to improve occupant comfort by reducing glare as well as reducing heat gain in the space. While this is a fairly common control strategy in Europe, it is not often applied in the US today. Savings depend upon the type of shading used and the control algorithm applied. System benefits may apply to both energy usage and productivity.

b. Integration and Interface: Lighting control system manufacturers have been slow to embrace open protocol standards. There are systems available that follow standards including DALI (for addressable ballasts) and BACnet. Most systems that are not based on open standards do have open protocol gateways available. The Smart Building interface to the lighting control system needs to allow both monitoring and control. This will not only allow operators with proper access to view and modify the system, but also enable the use of automated inter-system strategies for further energy savings. Note that the current P-100 standard is for a monitoring only interface. 
3. Energy Meters: Energy meters provide an invaluable tool for monitoring and measuring energy usage. The current Advanced Metering Initiative is focused on providing building level energy measurement from all facilities. As part of the Smart Building program, we are recommending installation of sub-meters for energy as well as other utilities including water.

a. Recommended Application: Meters are not typically used as a part of an automated optimization algorithm, but rather provide a tool for analysis and influencing tenant behavior. This includes:

i. Sub-System Metering: Where possible segment energy use by primary sub-system. For example electric energy use could be broken down by HVAC, lighting, data center, plug load, etc. Providing system metering information is an invaluable tool for measurement and ongoing programs for efficiency improvement.

ii. Tenant Sub-Metering and Revised Lease Terms: Presently GSA tenants are charged an allocated fee for energy usage. We would recommend installing sub-meters for each tenant, where feasible. This would allow for measurement of energy usage for each tenant and the ability to provide this information to the tenant to influence their usage patterns. The second part of this program would be to revise tenant agreements and charge tenants fees that are based on their actual energy usage. Many private sector developers have found that making tenants responsible for energy costs provides a strong incentive to having them participate in energy saving programs.

b. Integration and Interface: Meters including primary and submeters should be connected to the facility network for integration. Most meters are readily available with open protocol interfaces including Modbus and OPC. The Smart Building interface to the power meters needs to be allowed for monitoring only. Information from the meters will be used by operators on site and by energy managers at the regional and national level.

4. Fire and Life Safety: Fire and life safety systems are a necessary tool for property and occupant protection. The design, construction, installation and operation of these systems are controlled by a rigorous set of codes and standards. Integration of these systems provides value for operations in being able to view the status of alarms from both systems as well as trouble and other potential problems.

a. Integration and Interface: We would recommend that fire and life safety systems be completely standalone systems with dedicated wiring as required by codes and standards. Integration should only occur at the front end of the system and should be to provide secondary annunciation. The Smart Building interface to fire and life safety is to allow for monitoring only. Information from the fire and life safety system will be used by operators on site and remotely in addition to the information available at code mandated panels and 
stations. Note that this proposed integration is not to be used for any type of control including engineered smoke control. Smoke control should be implemented using a properly designed and listed UL-UUKL system.

5. Physical Access Control Systems (PACS): While of a lower priority, there are several potential benefits to designing a Smart Building strategy that includes access control. The first is a unified communications network. Running the access control system over an in building and wide area network has the potential to readily share common databases of smart card access information. This has the benefit of allowing and tracking access by Federal Employees to all authorized sites. The second benefit is in the use of access information as an indicator for use in occupancy-based scenarios. For example, this information can be used to bring on lights and HVAC when a space is accessed outside of normal occupancy hours and can also potentially be used to measure occupancy for demand based ventilation strategies.

a. Integration and Interface: Generally, access control systems are standalone per floor with their own dedicated readers and door control units. These systems would share the network infrastructure typically between floors and often between buildings. Additionally an interface to the card access application (which is typically done to a database) can be used to obtain anonymous occupancy information. The Smart Building interface to access control is to allow for monitoring only.

6. Security Cameras: Transitioning closed circuit TV (CCTV) video surveillance systems to IP based systems has many benefits including lower cost, greater flexibility and improved recording quality and analytics with the use of network-based video recorders (NVR).

a. Integration and Interface: We would recommend that the CCTV system be integrated on the building network for data transport only. Information from the CCTV system would travel over this network from the cameras to one or more NVRs. In order to protect privacy and security, CCTV camera information would not be readily accessible to any personnel other than security and would not be integrated with other systems.

7. Other Systems: There will be a number of additional systems in buildings which we have not covered in these recommendations. Examples include:

- Elevators

- Back up power and emergency generators

- Power quality monitoring

- Data center equipment (UPS, CRAC units)

- Chemical, biological, and radioactive substance detection

- Water treatment

- Mass notification

- $\mathrm{A} / \mathrm{V}$ 
- Digital signage

- Other specialized systems

We are not generally recommending that these systems be prepared for integration, however individual project teams need to carefully evaluate if there is any value and benefit to be obtained in energy, operations, or security in providing integration.

8. Network Infrastructure and Converged Networks: Implementing a Smart Building program requires a robust, secure, IP enabled network infrastructure. This infrastructure is primarily to support the systems listed above and to provide connectivity between buildings and regional centers. Expansion of this network has the capability to provide other required GSA functions including offering voice, data and video connectivity for Federal tenants. While this project did not evaluate the requirements for development or support of tenant networks, a parallel investigation was conducted by FAS and Noblis and determined that the following work is required:

a. Evaluate market readiness and capacity to recover costs for PBS provision and management of a broadband IP backbone capable of carrying voice, video, and data traffic as well as the collection and dissemination of building monitoring and control data. The infrastructure would also carry standard Public Switched Telecommunications Network (PSTN) traffic and will have provisions for interfacing with wireless systems as required.

b. If a positive business decision is made, develop network requirements for security, redundant paths, uninterrupted power and management.

i. Ensure that building wiring infrastructure meets all FAS ITS requirements.

ii. Ensure that building wiring is compatible with all interface requirements.

c. Manage converged networks as a building utility, available and fully operational to tenants at time of occupancy.

d. Pre-coordinate with tenants prior to occupancy that all telecom and IT services have been selected, pre-ordered, and LAN requirements have been defined and arrangements made for installation.

e. If a negative business decision is reached on provision of a converged network, validate business case for a deployment of a network dedicated to building monitoring and control data. Preliminary data indicates that simple payback for such a network is less than five years.

The conclusion of this study concurs with the disposition described above with the following additional considerations:

- While the first cost of various levels of network infrastructure is understood, and the operating costs can be determined, the [tenant] benefits remain unknown quantitatively. 
- Converged networks present a variety of challenges that must be addressed in order for them to be successful as a GSA-provided utility. These challenges include ownership, service, support, maintenance, and tenant willingness to subscribe.

- As the FAS/Noblis study concluded, further research is required to understand needs, potential usage, and requirements.

\section{Strategy 2. Systems Integration:}

The second strategy focuses on interconnecting the optimized building systems described in Strategy 1 above. There are many benefits to this integration in helping to deliver on the desired project goals. This is also a key step providing the necessary infrastructure required for Strategy 3 - Enterprise Operations.

Systems integration provides the ability to collect information from building systems and to use this combined information for advanced optimization algorithms as well facility operations. Technically this is achieved using hardware and software often referred to as "middleware". These middleware packages are readily available today from most of the major BAS suppliers. The middleware packages typically provide several functions including:

- Building System Open Protocol Support: Readily sharing information (both monitoring and control) with systems that utilize open standard protocols including BACnet and LonTalk. This allows for easy integration with most BAS (HVAC control) systems as well as many lighting, metering, life safety and other systems.

- IT Open Protocol Support: The systems are able to readily import and export data to IT applications including databases, web pages, and other applications including access control, financial management and other programs that support standards based on XML and Web Services.

- $\quad$ Proprietary Protocol Support: Many suppliers provide a broad catalog of data gateways that are able to integrate older or proprietary systems. This is done through protocol translation using a gateway function that translates the proprietary protocol to an open standard used by the middleware package.

- Web Page Display: The middleware packages provide a rich, web based user interface for facility management. These typically consist of a graphical user interface with real time information from all connected building systems. Using this function, a series of specialized user interfaces or portals can be developed for different user groups. For example, one view may be developed for the operations contractor, another for energy managers, and a third for occupants. Web based interfaces enable easy use from PC's running a web browser, or alternate devices including PDA's and Smart Phones that provide easy, secure, mobile access.

- Cross System Optimization: Using a middleware package facilitates standard processes for common system functions including alarm management, scheduling, trending and reporting. This allows operations to have a single view for all system problems and issues. It also is possible to use these systems to share information between systems. For example, when a user 
swipes their card for after hours access the middleware system sees this entry and automatically brings on the necessary lights and HVAC.

\section{Energy Optimization:}

Systems integration provides the ability for energy consuming systems (primarily HVAC and Lighting) to utilize shared information from other systems for further optimization. Some examples include:

Scheduling and Occupancy Based Control: Smart Buildings have the ability to use data from a variety of systems to properly schedule HVAC and lighting services. This starts with a standard operator provided schedule based on anticipated building occupancy. This is a common schedule for both lights and HVAC but uses the required optimization algorithms for each system. For example, the system calculates what time the HVAC system needs to start to have the building at the desired temperature at start of the designated occupancy time, and knows to flash the lights five minutes before they are scheduled to turn off at the end of the day so that occupants can override if needed. Systems integration will often use other systems for occupancy information as well. For example, information from the motion sensors for security can be used to shut off lights and HVAC in unoccupied areas, or the presentation of an access card after normal operating hours can bring on lights and HVAC for a designated period of time. It is even possible to use information about when a room is scheduled to be occupied (such as Microsoft Exchange conference room reservations) to schedule the comfort systems for that space. These strategies are extensions of the occupancy based control discussed under lighting control and can result in additional energy savings depending on how applied.

\section{Operations Optimization:}

Unified Interface: Systems integration allows facility operations and maintenance staff to have a unified user interface with information from all building systems on one set of web pages. This provides a valuable tool for more efficient operations. For example selecting a floor of a building will display the current floor plan with the current conditions including temperatures, light conditions, fire alarm status, energy usage, and occupancy information displayed. Clicking on a particular piece of equipment brings up a more detailed page for further troubleshooting. Using these pages, operators are able to better respond to tenant needs and identify problems. The system also has the ability to diagnose and prioritize alarms, routing them to the appropriate technicians. These can include links to required documents or instructional materials including video files to assist in resolving problems.

Mobile Operations: Systems integration allows service technicians to receive work orders and alarms and the BAS user interface from mobile devices including laptops, PDA's and Smart Phones. Mobile operations support provides the ability to improve tenant response time and technician productivity. For example, when a tenant reports a problem using the national call center or a web portal, a work order is generated and automatically dispatched to a technician's phone. They can view the 
work order and bring up a display showing the relevant system status. Using this information they may be able to resolve the problem online, or they can gather information to have the correct tools and parts to perform a repair. Since the system is web enabled, supervisors on site or at a remote operations center have the ability to view the systems as well, assisting the technician with troubleshooting, parts identification, and analysis.

Reports and Analysis: These systems also provide the ability to provide summarized and historical data in a series of reports and graphs. Common reports include details on equipment maintenance and energy usage. Many systems now go even further providing tools for continuous commissioning, fault detection and diagnostics. The end result is that these systems are often able to identify inefficiencies that an operator may not notice. Also connecting the building systems to other programs, such as CMMS, provides the ability for better preventative maintenance procedures and tracking. For example instead of requiring service for a piece of equipment on a fixed time interval, the system can track the number of hours of device run time and schedule service based on actual usage.

The anticipated result from systems integration is a series of tools that provides both an improvement in energy savings due to automated optimization and improved operations data as well as improved operations efficiency, allowing for use of fewer staff and lower operations costs.

\section{Strategy 3. Enterprise Management:}

The final strategy is the development of an Enterprise Management approach. This approach is widely used today by organizations that operate large property portfolios including university campuses, school districts, state government, and corporate facilities. The concept is to centralize the collection and analysis of facility information and to provide staffing and tools to more effectively provide tenant response and property management. This strategy fits with existing GSA programs including the new National Call Center.

Building Operations Centers (BOC): The concept of a BOC is to provide a central resource center focused on facility operations. There are several key functions that these centers provide, including:

- Operations Management: Operations management is focused on providing the tools and programs to assist in providing tenant support and evaluating operations contractor performance. Tenant calls would come into these centers and would be entered into the relevant work order (CMMS) system. Call tracking and follow up and contractor dispatching would also be processed by this group. Since operations management would also have access to all building systems, they would be able to receive and process system alarms. The operations center would provide monitoring of all buildings during hours when they do not have local operations staff available and would provide backup and support for the on site staff. Providing this type of management results in both improved tenant performance and can dramatically cut the staffing needs on site for operations. 
- Energy Management: Energy managers located at the BOC would have responsibility to monitor and track energy usage and to work with the operations staff to improve energy efficiency. This starts with an extension to the existing advanced metering program (SAPI) program to include extensive sub-metering data. Buildings would be measured on industry standard benchmarks, and tools to evaluate and compare facilities would be provided.

- Analytics and Analysis: Sophisticated software programs with the ability to evaluate building equipment and systems and to make decisions regarding operations and efficiency are starting to become available. These analytic packages use a large scale database of equipment and design parameters and are able to identify devices that are not operating properly and in many cases assess the cost of non-compliance. Since these are automated systems, they are able to look at buildings both during normal operations as well as during hours when operators are not typically on site such as during nights and weekends. These systems are an important tool in ongoing performance management and in minimizing both operations and energy costs.

- Building performance labeling: The GSA should take a leadership position in establishing a Building Energy Performance and Sustainability Certificate program. This would be similar to the labeling program initiated in the EU whereby buildings are labeled according to their energy performance and greenhouse gas emissions, with this information available to the public. Enterprise management can facilitate the collection of data to support this, and to maintain it.

- Support for disaster management and continuity of operations (COOP): By being able to readily connect to all building systems-including energy systems, life safety, and security-the BOC can serve to augment or replace on site operations in the event of a disaster.

- $\quad$ Network and IT Support: Providing support for converged communications networks in buildings will require ongoing support for tenant and facility moves, adds, and changes. The BOC has the ability to provide a centralized facility to support these functions and to monitor system issues, intrusions and faults.

\section{BOC Development}

The Buildings Operation Center (BOC) functionality is designed to be available wherever there is secure network connectivity. There are a number of options for deployment of these centers. While the decision as to how these are implemented is outside of the scope of this report, careful consideration should be given to allocation of this function to national or regional centers. 


\section{Appendix C: Financial Analysis Assumptions}

\section{Assumptions}

The following sections summarize and explain the rationale and sources of the various costs and savings applied in the financial analysis as well as other assumptions used in the analysis.

\section{Operating Costs}

We established baseline operating costs for energy and operations (Table C-1) based on GSA data, where available, industry practice and other reports.

Table C-1: Summary of operating costs

\begin{tabular}{|l|r|}
\hline \multicolumn{1}{|c|}{ Strategy } & \multicolumn{1}{|c|}{$\begin{array}{c}\text { Estimated Cost } \\
\left(\mathbf{\$} / \mathrm{ft}^{\mathbf{2}} / \text { year) }\right.\end{array}$} \\
\hline Energy & $\$ 1.93$ \\
\hline Operations & $\$ 3.70$ \\
\hline Total (per square foot) & $\$ 5.63$ \\
\hline
\end{tabular}

\section{Energy}

GSA energy cost intensity estimate: $\mathbf{\$ 1 . 9 3}$ per square foot per year.

- For the GSA portfolio, an average energy cost intensity of $\$ 1.93$ per square foot per year was provided by the GSA.

- As a point of reference, the Energy Information Administration 2003 CBECS data yields an energy cost intensity of $\$ 1.71$ per square foot per year for commercial office buildings.

\section{Operations}

GSA operations cost intensity estimate: $\$ 3.70$ per square foot per year.

- Operations cost includes monitoring and management by facility managers and building operators/engineers, maintenance, and cleaning.

- Per the GSA, operations cost is estimated at $\$ 3.70$ per square foot per year.

\section{Implementation Investment}

Implementation costs for each strategy are estimated on a per square foot basis. Table C-2 lists the estimated costs, and the sections that follow describe how the costs are derived. 
Table C-2: Estimated implementation costs per strategy

\begin{tabular}{|l|r|}
\hline \multicolumn{1}{|c|}{ Strategy } & \multicolumn{1}{|c|}{$\begin{array}{c}\text { Estimated Cost } \\
\left(\mathbf{\$} / \mathbf{f t}^{\mathbf{2}} \mathbf{)}\right.\end{array}$} \\
\hline High performance building core & $\$ 0.35$ \\
\hline Systems integration & $\$ 0.22$ \\
\hline Enterprise operations & $\$ 0.29$ \\
\hline Total (per square foot) & $\$ 0.86$ \\
\hline
\end{tabular}

See Table C-4 for the supporting arguments and rationale associated with investment.

\section{Estimated Savings}

Savings are estimated as percentage improvement in energy efficiency and operations productivity yielded by each strategy. This is in turn translated into financial terms. Table C-2 below summarizes the percentage improvement in energy and operations for each strategy.

Table C-2: Estimated energy and operations improvements

\begin{tabular}{|c|c|c|}
\hline \multirow[t]{2}{*}{ Strategy } & \multicolumn{2}{|c|}{$\begin{array}{l}\text { Estimated Percentage Improvement } \\
\qquad\left(\$ / \mathrm{ft}^{2} / \text { year }\right)\end{array}$} \\
\hline & Energy & Operations \\
\hline High performance building core & $0.0 \%$ & $2.0 \%$ \\
\hline Systems integration & $2.0 \%$ & $5.0 \%$ \\
\hline Enterprise operations & $2.0 \%$ & $5.0 \%$ \\
\hline Total & $4.0 \%$ & $12.0 \%$ \\
\hline
\end{tabular}

See Table C-5 for the supporting arguments and rationale behind the projected savings. 
Table C-4a: Estimated investment for Smart Buildings

\begin{tabular}{|c|c|c|c|}
\hline \multirow[t]{2}{*}{ Strategy } & \multicolumn{3}{|c|}{ Estimated Investment: Costs, Assumptions and Rationale } \\
\hline & Elements & Cost $\left(\$ / f t^{2}\right)$ & Assumptions \& Rationale \\
\hline \multirow{8}{*}{$\begin{array}{l}\text { High performance } \\
\text { building control core }\end{array}$} & HVAC controls & $\$ 0.0$ & Included in base stimulus plan. \\
\hline & Lighting controls & $\$ 0.0$ & Included in base stimulus plan. \\
\hline & Metering & $\$ 0.0$ & Included in base stimulus plan. \\
\hline & Security & $\$ 0.0$ & Provisions included in network infrastructure for future integration of security. \\
\hline & Commissioning & $\$ 0.0$ & Included in base stimulus plan. \\
\hline & Recommissioning & $\$ 0.0$ & Included in base stimulus plan. \\
\hline & Network infrastructure & $\$ 0.35$ & Support for all building systems. \\
\hline & Subtotal & $\$ 0.35$ & $\$ 52.5 \mathrm{M}$ \\
\hline \multirow[t]{3}{*}{ Systems integration } & Middleware/integration & $\$ 0.20$ & $\$ 50,000$ per building, plus 10,000 per $100,000 \mathrm{ft}^{2}$ includes hardware/software/labor \\
\hline & Engineering \& design & $\$ 0.02$ & Plus engineering/design fees at $10 \%$ of estimated cost \\
\hline & Subtotal & $\$ 0.22$ & \$33.0M \\
\hline \multirow[t]{5}{*}{ Enterprise operations } & Software & $\$ 0.07$ & Estimated at $\$ 10 \mathrm{M}$. \\
\hline & Operations center(s) & $\$ 0.13$ & Estimated at $\$ 10 \mathrm{M}$. \\
\hline & Processes and training & $\$ 0.07$ & Estimated at $\$ 10 \mathrm{M}$. \\
\hline & Engineering \& design & $\$ 0.03$ & Plus engineering/design fees at $10 \%$ of estimated cost \\
\hline & Subtotal & $\$ 0.29$ & $\$ 44.0 M$ \\
\hline Total & & $\$ 0.86$ & \\
\hline
\end{tabular}

Table C-4b: Estimated incremental investment for converged networks

\begin{tabular}{|c|c|c|c|c|}
\hline \multirow[t]{2}{*}{ Expansion Option } & \multicolumn{4}{|c|}{ Estimated Investment for Expanded Network Infrastructure } \\
\hline & Options & $\begin{array}{l}\text { Incremental } \\
\text { Cost }\left(\$ / \mathrm{ft}^{2}\right)\end{array}$ & $\begin{array}{l}\text { Core Cost } \\
\left(\$ / \mathrm{ft}^{2}\right)\end{array}$ & $\begin{array}{c}\text { Description } \\
\text { (See Appendix F for more details) }\end{array}$ \\
\hline \multirow[t]{3}{*}{ Converged Networks } & Network infrastructure & $\$ 0.0$ & $\$ 0.86$ & Support for all building systems, included in core. \\
\hline & Expansion Option [a] & $\$ 0.30$ & $\$ 1.51$ & Plus selected services. \\
\hline & Expansion Option [b] & $\$ 0.65$ & $\$ 1.86$ & Plus expanded services and high reliability. \\
\hline
\end{tabular}


Table C-5: Estimated energy and operations savings for Smart Buildings ( 1 of 2)

\begin{tabular}{|c|c|c|}
\hline \multirow[t]{2}{*}{ Strategy } & \multicolumn{2}{|c|}{ Estimated Savings: Percentage Improvement, Assumptions and Rationale } \\
\hline & Energy & Operations \\
\hline \multirow{2}{*}{$\begin{array}{l}\text { High } \\
\text { performance } \\
\text { building core }\end{array}$} & $0.0 \%$ & $2.0 \%$ \\
\hline & $\begin{array}{l}\text { - Building systems optimization results in 2-30\% energy savings } \\
\text { - HVAC system optimization yields 2- } 20 \% \mathrm{HVAC} \text { energy savings, } \\
\text { primarily for central plants and air distribution. } \\
\text { - Lighting controls optimization yields } 6-10 \% \text { improvement in lighting } \\
\text { - The potenticiency } \\
\text { building and its systems. } \\
\text { Note: energy savings associated with the high performance building core } \\
\text { elements funded as part of the economic stimulus are not included here. } \\
\text { Energy savings associated with the high performance building control core } \\
\text { are estimated at an average of } 10 \% \text {. }\end{array}$ & $\begin{array}{l}\text { - Basic network infrastructure to support building systems and facilitate } \\
\text { integration and IP connectivity facilitates access to building systems } \\
\text { through web-based user interfaces including mobile devices, and } \\
\text { provides the foundation for enterprise management. } \\
\text { - A very conservative } 2 \% \text { improvement is estimated. }\end{array}$ \\
\hline \multirow{2}{*}{$\begin{array}{l}\text { Systems } \\
\text { integration }\end{array}$} & $2.0 \%$ & $5.0 \%$ \\
\hline & $\begin{array}{l}\text { Greater opportunity for energy cost savings come from increased } \\
\text { awareness of building system performance issues and real time } \\
\text { resolution of such issues enabled by integrating building systems and } \\
\text { tools such as advanced web-based user interfaces and mobile devices. } \\
\text { - Cross optimization of systems results in improved scheduling of lights } \\
\text { and HVAC, potential coordination and sequencing improvements, and } \\
\text { feedback on maintenance issues, such as improper setpoints and } \\
\text { operating parameters, etc. The energy savings that can be achieved } \\
\text { through integration need to be studied on a project by project basis. } \\
\text { - Rapid response to building performance issues avoids the cost of } \\
\text { allowing building performance issues to go unnoticed and } \\
\text { uncorrected. }\end{array}$ & $\begin{array}{l}\text { - High performance and integration-ready systems with state-of-the-art } \\
\text { user interfaces and a high data availability better support building } \\
\text { operations, including monitoring, maintenance, and troubleshooting. } \\
\text { For example: } \\
\text { ○ Faster troubleshooting and resolution of comfort issues. } \\
\text { - Better informed decision making for maintenance and repairs, } \\
\text { decreasing time spent and rework. } \\
\text { - Unified and highly accessible user interface will enable building } \\
\text { management staff to achieve comfort and expertise across all } \\
\text { systems and to work flexibly with greater mobility. Furthermore, } \\
\text { such systems enable analysis and troubleshooting. } \\
\text { Systems that share infrastructure, tools, and user interface reduce } \\
\text { overall training needs. }\end{array}$ \\
\hline
\end{tabular}


Table C-5: Estimated energy and operations savings for Smart Buildings ( 2 of 2)

\begin{tabular}{|c|c|c|}
\hline \multirow[t]{2}{*}{ Strategy } & \multicolumn{2}{|c|}{ Estimated Savings: Percentage Improvement, Assumptions and Rationale } \\
\hline & Energy & Operations \\
\hline \multirow{2}{*}{$\begin{array}{l}\text { Enterprise } \\
\text { operations }\end{array}$} & $2.0 \%$ & $5.0 \%$ \\
\hline & $\begin{array}{l}\text { Comprehensive and knowledgeable oversight of buildings at regional } \\
\text { or national operations centers facilitate rapid identification and } \\
\text { resolution of building performance issues. } \\
\text { - Building performance can be compared across facilities, establishing a } \\
\text { basis for identifying problematic energy efficiency levels in need of } \\
\text { attention. }\end{array}$ & $\begin{array}{l}\text { - Building performance can be compared across facilities, establishing a } \\
\text { basis upon which to address and prioritize maintenance and projects. } \\
\text { - Centralized management and tracking of maintenance and work } \\
\text { orders consolidates administration of this work, and allows for it to be } \\
\text { performed with greater efficiency and accountability. }\end{array}$ \\
\hline Total & $4.0 \%$ & $12.0 \%$ \\
\hline
\end{tabular}




\section{Appendix D: Detailed Financial Analysis Summary and Pro-forma}

Table D-1: Detailed analysis summary

\begin{tabular}{|c|c|c|c|}
\hline & Energy & Operations & \begin{tabular}{|c|} 
Total \\
Energy + Operations
\end{tabular} \\
\hline Estimated Operating Cost & \multicolumn{3}{|c|}{$\left(\$ / \mathrm{ft}^{2} /\right.$ year $)$} \\
\hline Cost / square foot / year & $\$ 1.93$ & $\$ 3.70$ & $\$ 5.63$ \\
\hline Anticipated Changes & \multicolumn{3}{|c|}{ (\%) } \\
\hline High performance building core & $0.0 \%$ & $2.0 \%$ & $2.0 \%$ \\
\hline Systems integration & $2.0 \%$ & $5.0 \%$ & $7.0 \%$ \\
\hline Enterprise operations & $2.0 \%$ & $5.0 \%$ & $7.0 \%$ \\
\hline Total & $4.0 \%$ & $12.0 \%$ & \\
\hline Estimated Savings & \multicolumn{3}{|c|}{$\left(\$ / \mathrm{ft}^{2} /\right.$ year $)$} \\
\hline High performance building core & $\$ 0.00$ & $\$ 0.07$ & $\$ 0.07$ \\
\hline Systems integration & $\$ 0.04$ & $\$ 0.19$ & $\$ 0.22$ \\
\hline Enterprise operations & $\$ 0.04$ & $\$ 0.19$ & $\$ 0.22$ \\
\hline Total & $\$ 0.08$ & $\$ 0.44$ & $\$ 0.52$ \\
\hline Estimated Investment & \multicolumn{3}{|c|}{$\left(\$ / \mathrm{ft}^{2}\right)$} \\
\hline High performance building core & $\$ 0.35$ & $\$ 0.35$ & $\$ 0.35$ \\
\hline Systems integration & $\$ 0.22$ & $\$ 0.22$ & $\$ 0.22$ \\
\hline Enterprise operations & $\$ 0.29$ & $\$ 0.29$ & $\$ 0.29$ \\
\hline Total & $\$ 0.86$ & $\$ 0.86$ & $\$ 0.86$ \\
\hline Simple Payback & \multicolumn{3}{|c|}{ (years) } \\
\hline High performance building core & & 4.73 & 4.73 \\
\hline Systems integration & 5.70 & 1.19 & 0.98 \\
\hline Enterprise operations & 7.60 & 1.59 & 1.31 \\
\hline Total & 11.18 & 1.94 & 1.66 \\
\hline
\end{tabular}


GSA

Table D-2: Pro-Forma with energy benefits only

\begin{tabular}{|c|c|c|c|c|c|c|c|c|c|c|c|}
\hline \multicolumn{12}{|l|}{ Cash flow and ROI statement } \\
\hline BENEFIT DRIVERS & \multicolumn{11}{|c|}{ YEAR } \\
\hline Net Savings (as a result of changes/improvements) & & & & & & & & & & & \\
\hline High performance building core & & $\$ 0$ & $\$ 0$ & $\$ 0$ & $\$ 0$ & $\$ 0$ & $\$ 0$ & $\$ 0$ & $\$ 0$ & $\$ 0$ & $\$ 0$ \\
\hline Systems integration & & $\$ 5,790$ & $\$ 5,790$ & $\$ 5,790$ & $\$ 5,790$ & $\$ 5,790$ & $\$ 5,790$ & $\$ 5,790$ & $\$ 5,790$ & $\$ 5,790$ & $\$ 5,790$ \\
\hline Enterprise operations & & $\$ 5,790$ & $\$ 5,790$ & $\$ 5,790$ & $\$ 5,790$ & $\$ 5,790$ & $\$ 5,790$ & $\$ 5,790$ & $\$ 5,790$ & $\$ 5,790$ & $\$ 5,790$ \\
\hline Total annual benefits & & $\$ 11,580$ & $\$ 11,580$ & $\$ 11,580$ & $\$ 11,580$ & $\$ 11,580$ & $\$ 11,580$ & $\$ 11,580$ & $\$ 11,580$ & $\$ 11,580$ & $\$ 11,580$ \\
\hline Implementation filter & & $95 \%$ & $95 \%$ & $95 \%$ & $95 \%$ & $95 \%$ & $95 \%$ & $95 \%$ & $95 \%$ & $95 \%$ & $95 \%$ \\
\hline Total benefits realized & & $\$ 11,001$ & $\$ 11,001$ & $\$ 11,001$ & $\$ 11,001$ & $\$ 11,001$ & $\$ 11,001$ & $\$ 11,001$ & $\$ 11,001$ & $\$ 11,001$ & $\$ 11,001$ \\
\hline Costs & Year 0 & Year 1 & Year 2 & Year 3 & Year 4 & Year 5 & Year 6 & Year 7 & Year 8 & Year 9 & Year 10 \\
\hline $\begin{array}{l}\text { Ongoing Support Costs } \\
\text { Training Costs }\end{array}$ & $\$ 12900$ & $\$ 8$ & $\$ 8$ & $\$ 8$ & $\$ 8$ & $\$ 8$ & $\$ 8$ & $\$ 8$ & $\$ 8$ & $\$ 8$ & $\$ 8$ \\
\hline $\begin{array}{l}\text { Initial investment } \\
\text { Total }\end{array}$ & $\$ 129,500$ & $\$ 8$ & $\$ 8$ & $\$ 8$ & $\$ 8$ & $\$ 8$ & $\$ 8$ & $\$ 8$ & $\$ 8$ & $\$ 8$ & $\$ 8$ \\
\hline Benefits & Year 0 & Year 1 & Year 2 & Year 3 & Year 4 & Year 5 & Year 6 & Year 7 & Year 8 & Year 9 & Year 10 \\
\hline Annual benefit flow & $(\$ 129,500)$ & $\$ 10,993$ & $\$ 10,993$ & $\$ 10,993$ & $\$ 10,993$ & $\$ 10,993$ & $\$ 10,993$ & $\$ 10,993$ & $\$ 10,993$ & $\$ 10,993$ & $\$ 10,993$ \\
\hline Cumulative benefit flow & $(129,500)$ & $(118,507)$ & $(107,513)$ & $(96,520)$ & $(85,527)$ & $(74,534)$ & $(63,540)$ & $(52,547)$ & $(41,554)$ & $(30,560)$ & $(19,567)$ \\
\hline Discounted benefit flow & Year 0 & Year 1 & Year 2 & Year 3 & Year 4 & Year 5 & Year 6 & Year 7 & Year 8 & Year 9 & Year 10 \\
\hline Discounted costs & $\$ 129,500$ & $\$ 0$ & $\$ 0$ & $\$ 0$ & $\$ 0$ & $\$ 0$ & $\$ 0$ & $\$ 0$ & $\$ 0$ & $\$ 0$ & $\$ 0$ \\
\hline Discounted benefits & & 11,001 & 11,001 & 11,001 & 11,001 & 11,001 & 11,001 & 11,001 & 11,001 & 11,001 & 11,001 \\
\hline Total discounted benefit flow & $(129,500)$ & 11,001 & 11,001 & 11,001 & 11,001 & 11,001 & 11,001 & 11,001 & 11,001 & 11,001 & 11,001 \\
\hline Total cumulative discounted benefit flow & $(129,500)$ & $(118,499)$ & $(107,498)$ & $(96,497)$ & $(85,496)$ & $(74,495)$ & $(63,494)$ & $(52,493)$ & $(41,492)$ & $(30,491)$ & $(19,490)$ \\
\hline Initial investment & Year 0 & Year 1 & Year 2 & Year 3 & Year 4 & Year 5 & Year 6 & Year 7 & $\begin{array}{ll}\text { Year } 8 \\
-1\end{array}$ & Year 9 & Year 10 \\
\hline Net Investment & & & & & & & & & & & \\
\hline $\begin{array}{l}\text { High performance building core } \\
\text { Systems integration }\end{array}$ & $\begin{array}{l}\$ 52,500 \\
\$ 33,000\end{array}$ & & & & & & & & & & \\
\hline $\begin{array}{l}\text { Enterprise operations } \\
\text { Net }\end{array}$ & $\$ 44,000$ & $\leqslant 0$ & $\leqslant 0$ & $\leqslant 0$ & 50 & 50 & 50 & \$0 & 50 & so & so \\
\hline $\begin{array}{l}\text { Net Investment } \\
\text { Total }\end{array}$ & $\begin{array}{l}\$ 129,500 \\
\$ 129,500\end{array}$ & $\begin{array}{llll}50 \\
50\end{array}$ & $\$ \frac{30}{50}$ & $\begin{array}{lll}50 \\
50\end{array}$ & $\frac{30}{50}$ & so & $\begin{array}{llll}50 \\
50\end{array}$ & 50 & 50 & 50 & \$0 \\
\hline
\end{tabular}

ROI measures

\begin{tabular}{|l}
\hline Cost of capital \\
\hline Ret present value \\
\hline
\end{tabular}

\begin{tabular}{|c|c|}
\hline & $0 \%$ \\
\hline & $(\$ 19,567)$ \\
\hline
\end{tabular}

\begin{tabular}{|l|l}
\hline Return on investmen \\
\hline Payback (in years) \\
\hline
\end{tabular}

After Year 3

\begin{tabular}{|l|l|l|l|l|l|l|l|l|l|}
\hline $8 \%$ & $17 \%$ & $25 \%$ & $34 \%$ & $42 \%$ & $51 \%$ & $59 \%$ & $68 \%$ & $76 \%$ & $85 \%$ \\
\hline
\end{tabular}

GSA Smart Buildings Report

April 8, 2009 
GSA

Table D-3: Pro-Forma with energy and operations benefits

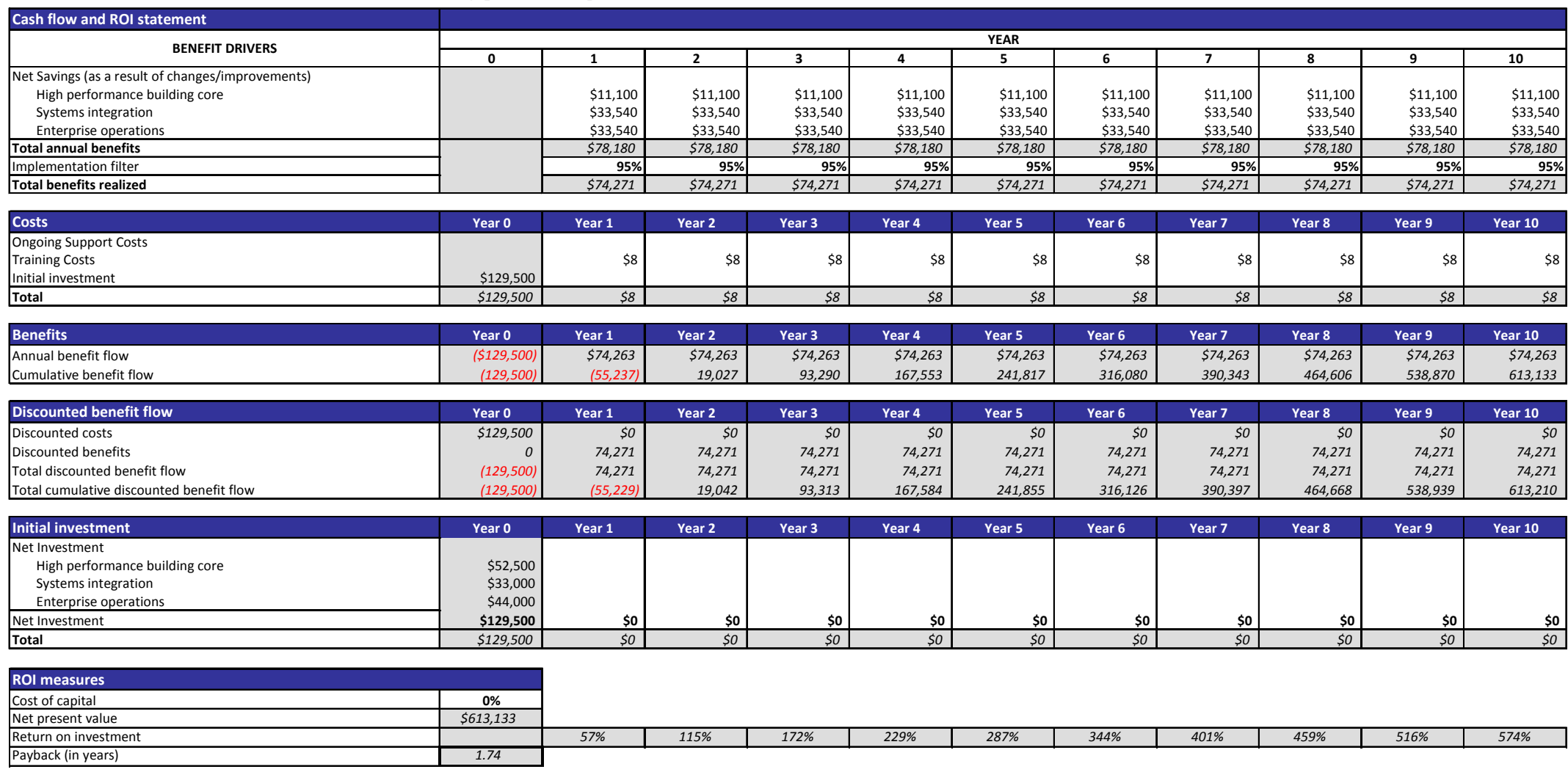

GSA Smart Buildings Report

April 8, 2009 


\section{Appendix E: Action Plan Scenarios}

The Action Plan Scenario Analysis addresses the following variables for Pilot Projects:
A. Number of pilot projects
B. Location (regional distribution) of pilot projects
C. Size of pilot projects
D. Type of pilot projects, new construction vs. renovation
E. Speed of roll-out (implementation)

For each of these variables we identify options, the pros and cons for each, and make a recommendation.

\section{A. Number of Pilot Projects}

\section{Background}

Pilot projects are needed to provide the actual costs and savings for smart building implementation as well as lessons learned about building performance, user satisfaction, and other benefits. Pilot projects could include recently completed smart building projects, projects currently underway, and new projects.

The issues related to the Number of the pilot projects are a follows:

1. Enough pilots are needed to learn about the variety of building types in the GSA portfolio.

2. Experience with smart buildings is not equally distributed across the Regions.

3. A critical mass of projects is needed within a Region in order to demonstrate a Regional Operating Center.

4. The costs of pilot projects will scale with the number of pilots implemented.

Scenarios for number of Pilot Projects:

\section{A-1. Zero pilots}

Pro:

- Least expensive option. (doesn't include costs due to problems that result from lack of knowledge of how to implement strategies)

- Enough information is already known about smart buildings in general that additional validation is not necessary

- Resources are spent immediately on wide-scale deployment, not individual pilots

Con:

- Not enough information is known about the actual costs and savings for GSA on smart buildings

- Resources may be poorly targeted if GSA starts with wide-scale deployment 


\section{A-2. One pilot}

Pro:

- Less expensive option. [\$100k for demonstration and evaluation per pilot]

- Some additional information will be learned about smart building deployment

Con:

- Information from one pilot may not generalize to the rest of GSA's portfolio

\section{A-3. Three pilots}

Pro:

- Less expensive option. [\$300k]

- Probably would provide useful information if three pilots are similar buildings with similar systems

Con:

- Not enough information to generalize across diverse stock

- Not all regions get to participate

\section{A-4. Eleven Pilots}

Pro:

- Moderately expensive option. [\$1.1M]

- Would likely provide enough information for deployment across portfolio

- Promotes regional equity, e.g., one pilot per Region

Con:

- Not all regions may be prepared or have prior experience for pilot demonstration

- Doesn't allow demonstration of a Regional Operating Center

\section{A-5. Thirty-three pilots}

Pro:

- Would generate sufficient information on the costs, benefits and lessons learned

- Would address all major building types found in the portfolio

- Promotes Regional equity, e.g., three pilots per Region

- Would allow demonstration of Regional Operating Centers

Con:

- Most expensive scenario. [\$3.3M]

- Not all regions may be prepared or have prior experience for pilot demonstration

\section{Recommendation:}

A-4. Eleven Pilots 
Additional recommendation(s):

- Include 2-3 additional pilots in one region for a total of 14 pilots, and demonstrate a Regional Operating Center. [additional $\$ 300 \mathrm{k}$ ]

- Provide additional resources where requested for Regions without prior experience in smart building implementation. [additional $\$ 300 \mathrm{k}$ ]

Total cost: $[\$ 1.7 \mathrm{~m}]$

\section{B. Location of Pilot Projects}

\section{Background}

The issues related to Location of pilot projects are as follows:

- Expertise and experience with smart building retrofits is not equally distributed across all Regions

- Regions with experience may be able to quickly conduct pilots

- Regions without experience may require additional resources

- Multiple pilots in the same region allow for the demonstration of a Regional Operating Center

Scenarios for Location of Pilot Projects:

\section{B-1. Pilots all in One Region}

Pro:

- Least expensive option.

- Could pick region with most experience and expertise for rapid demonstration

- Could demonstrate a Regional Operating Center

Con:

- Not equitable for other regions

- Wouldn't learn how start up costs would impact all regions

\section{B-2. Pilots in Three Regions}

Pro:

- Less expensive option.

- Some additional information would be learned about smart building deployment in different Regions

- Could demonstrate a Regional Operating Center if multiple pilots included in any one Region.

Con:

- Information from three Regions may not generalize to the rest of GSA's portfolio 


\section{B-3. Pilots in All Regions}

Pro:

- Would provide experience for all Regions

- Could demonstrate a Regional Operating Center if multiple pilots included in any one Region.

Con:

- Most expensive option.

- Regions without prior experience may require additional resources

\section{Recommendation:}

B-3. Pilots in All Regions

Additional recommendation:

- Establish a peer-to-peer team with representatives from each Region for Regions to learn from each other's experience.

\section{Size (Floor Area) of Pilot Projects}

\section{Background}

The issues related to the mix of the pilot project size (floor area) are as follows:

- Small projects could be demonstrated more quickly than large projects [?]

- Small projects may not have building automation systems that would be good candidates for smart building strategies

- A mix of small and large projects reflects the diverse GSA portfolio

- $80 \%$ of the GSA portfolio floor area is in buildings over $100,000 \mathrm{ft} 2$ [check]

- $50 \%$ of the GSA buildings are less than $100,000 \mathrm{ft} 2$ [check]

- The financials for smart building strategies tend to favor larger buildings

Scenarios for Size of Pilot Projects:

\section{C-1. Only Include Projects under $100,000 \mathrm{ft}^{2}$}

Pro:

- Smaller buildings may be easier to implement and evaluate

- GSA has a large number of small buildings

Con:

- Smaller buildings may not have building automation systems

- Smaller buildings may have worse paybacks for energy smart strategies 


\section{C-2. Include Projects split 50/50 over and under $100,000 \mathrm{ft}^{2}$}

Pro:

- Represents GSA's diverse portfolio of buildings.

Con:

- Smaller buildings may not have building automation systems

- Smaller buildings may have worse paybacks for energy smart strategies

\section{C-3. Only Include Projects over $100,000 \mathrm{ft}^{2}$}

Pro:

- Stimulus funds are likely to target the larger buildings

- Larger buildings most likely to have building automation systems

- Financials favor larger buildings

Con:

- Doesn't include smaller buildings

\section{Recommendation:}

C-3. Only Include Projects over $100,000 \mathrm{ft} 2$

Additional recommendation:

- Consider including 2-3 smaller buildings if they look like promising candidates, e.g., they have a smart building champion, existing building automation system, and/or a location in a Region considering a Regional Operating Center.

\section{Type of Pilot Projects (Retrofit vs. New Construction)}

\section{Background}

The issues related to the pilot project type (Retrofit vs. New Construction) are as follows:

- The stimulus funds are [nearly] all directed to existing buildings

- GSA will still be building new buildings

- The financials for smart building strategies are different for existing vs. new construction

Scenarios for Type of Pilot Projects:

\section{D-1. Only Include Existing Buildings}

Pro:

- Stimulus funds are likely to target existing buildings

- Existing buildings make up $99 \%$ of the GSA portfolio 
Con:

- GSA plans to build new buildings

- New buildings may be financially better targets for smart building strategies

\section{D-2. Include a mix of Existing Building and New Construction [90/10]}

Pro:

- Represents GSA's portfolio of buildings.

Con:

- New buildings have different requirements than existing buildings

\section{D-3. Only Include New Buildings}

Pro:

- New buildings may be financially better targets for smart building strategies Con:

- $\quad$ Stimulus funds are likely to target existing buildings

\section{Recommendation:}

D-1. Only Include Existing Buildings

Additional recommendation:

- Consider including 2-3 new buildings if they look like promising candidates, e.g., they have a smart building champion, and/or a location in a Region considering a Regional Operating Center.

\section{E. Speed of Roll-Out for Pilots (Implementation)}

\section{Background}

The issues related to the speed of roll out for the pilot projects are as follows:

- Deployment with stimulus funds could start in 2009

- Lessons from Pilots will need to be transferred to deployment projects in real time-not years later.

- Deployment of smart building strategies will require guidelines for design team and building operators, whether at the building or at Regional Operating Centers 
Scenarios for speed of roll-out for Pilot Projects:

\section{E-1. All Pilots start in 2009}

Pro:

- Lessons learned from pilots can be transferred to stimulus projects that start in 2010 and later

Con:

- Planning for pilot projects has not yet started

- Not all Regions may be ready for pilot projects in 2009

\section{E-2. Pilots start in 2009, 2010, 2011}

Pro:

- Lessons from initial pilots can be shared with next cycle of pilots and stimulus projects

Con:

- Some stimulus projects will start before pilots are underway

\section{E-3. Pilots start in $\mathbf{2 0 1 0}$}

Pro:

- There is sufficient time to plan for pilots

Con:

- Many stimulus projects will start before pilots are underway

\section{Recommendation:}

E-2. Pilots start in 2009, 2010, 2011

Additional recommendation:

- P-100 language, specifications, and guide books will be needed for stimulus projects to reflect best practices prior to the results from the pilot projects being available. 


\section{Appendix F: Network Infrastructure Options}

As stated in Part 2, central to and included in the High Performance Building Control Core is a vertical network infrastructure to support all building systems. While this network infrastructure may be expandable to a converged network that provides voice, video, and data services to tenants, it is only the basic vertical infrastructure that is recommended for implementation in Smart Buildings, as illustrated conceptually in Figure F-1. Options to expand the network infrastructure range in capability and cost, and two such options are presented here.

Table F-1: Converged Network Infrastructure Expansion Options

\begin{tabular}{|c|c|c|}
\hline $\begin{array}{l}\text { Vertical Network } \\
\text { Infrastructure }\end{array}$ & $\begin{array}{c}\text { Incremental } \\
\text { Cost } \\
\left(\$ / \mathrm{ft}^{2}\right)\end{array}$ & Description \\
\hline Base & $\$ 0.00$ & $\begin{array}{l}\text { [Included in the high performance } \\
\text { building control core.] } \\
\text { Enterprise class non-redundant fiber } \\
\text { backbone with support for building } \\
\text { systems only }\end{array}$ \\
\hline Converged: Option [a] & $\$ 0.30$ & $\begin{array}{l}\text { Base plus: } \\
\text { Additional switches to support selected } \\
\text { tenant services such as voice } \\
\text { communications. }\end{array}$ \\
\hline Converged: Option [b] & $\$ 0.65$ & $\begin{array}{l}\text { Option [a] plus: } \\
\text { Support for expanded capacity and } \\
\text { tenant services such as voice, video, } \\
\text { and data communications. } \\
\text { Dual pathways for redundancy and } \\
\text { reliability. }\end{array}$ \\
\hline
\end{tabular}

Note that in any case, various issues surrounding the common vertical network infrastructure must be addressed, including support, maintenance, and upgrades. For converged network options, such issues expand to include support for the tenant services and coordination with tenant agencies. 


\section{GSA}

Floor $n$

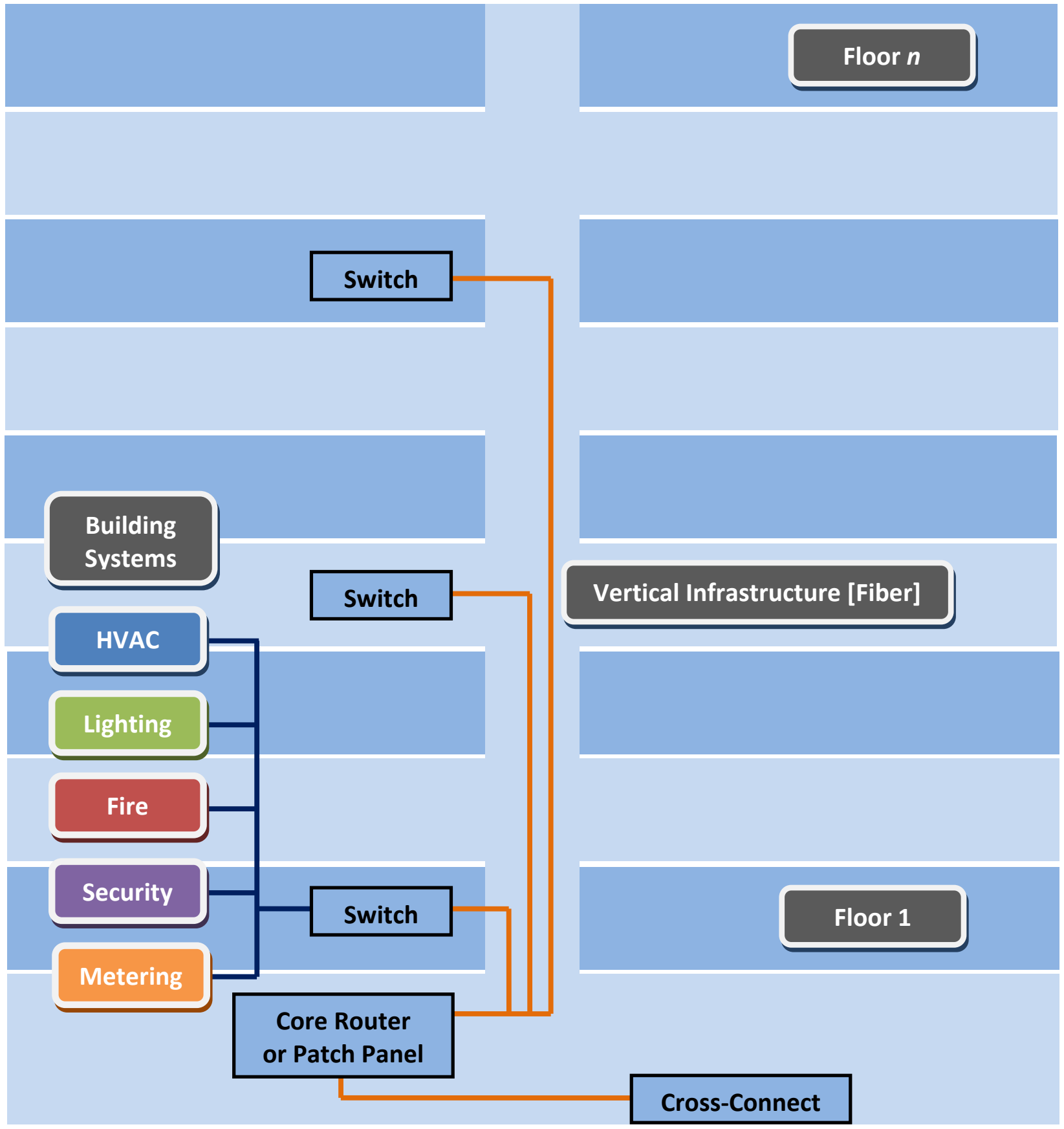

Figure F-1: Conceptual vertical network infrastructure 